\title{
Design of Cold Rolled and Continuous Annealed Carbide-Free Bainitic Steels for Automotive Application
}

\author{
F.G. Caballero ${ }^{\mathrm{a}}$, S. Allain ${ }^{\mathrm{b}}$, J. Cornide ${ }^{\mathrm{a}}$, J.D. Puerta Velásquez ${ }^{\mathrm{b}}$, C. Garcia-Mateo ${ }^{\mathrm{a}}$ and M.K. \\ Miller $^{\mathrm{c}}$
}

${ }^{a}$ Spanish National Center for Metallurgical Research (CENIM-CSIC), Avda Gregorio del Amo, 8; Madrid, E-28040, Spain, fgc@cenim.csic.es; jca@cenim.csic.es; cgm@cenim.csic.es ${ }^{\mathrm{b}}$ ArcelorMittal Maizieres Research SA, Voie Romaine, BP30320, 57283 Maizières-lès-Metz Cedex, France, sebastien.allain@arcelormittal.com; juan-david.puertavelasquez@arcelormittal.com

c Oak Ridge National Laboratory (ORNL), Materials Science and Technology Division; Oak Ridge, TN 37831-6139, millermk@ornl.gov

Corresponding Author:

F.G. Caballero

Spanish National Center for Metallurgical Research (CENIM-CSIC)

Av. Gregorio del Amo, 8

28040 MADRID

Spain

Tlf: +34 915538900 (Ext 373)

Fax +3491534 7425

E-mail: fgc@cenim.csic.es

\begin{abstract}
Advanced high strength steels for automotive applications were designed to achieve a carbide-free bainitic microstructure after conventional thermo-mechanical processing and a continuous annealing treatment. The microstructure obtained consists of ferrite laths interwoven with thin films of untransformed retained austenite. The sufficiently tough matrix and the control of the heterogeneity in the microstructure will allow an optimum combination of strength, ductility, and formability to be achieved. The designed steels reached far higher uniform elongations than that in commercial dual phase steels and martensitic steels with the same range of ultimate tensile strengths. Their formability was found to be appropriate for the production of final parts after cold-stamping or cold-forming. On the other hand, the yield strength/ ultimate tensile strengths ratio was found to remain roughly constant $(\sim 0.7)$. The reduction of area value did not seem to change as a function of overaging temperature, but the V-bending angle and the hole expansion ratio (cut-edge stretching ability) decreased significantly at the bainite holding temperature increases.
\end{abstract}

Keywords: carbide-free bainite, steel, annealing, automotive components, ductility, formability

\section{Introduction}


Potential future car technologies include new energy sources and new materials, which are being developed in order to make vehicles more sustainable, safer, more energy efficient, and less polluting. With rising oil prices, the future of cars is leaning towards increased fuel efficiency, energy savers, hybrid vehicles, battery electric vehicles, and fuel cell vehicles. Auto-makers are focused on weight reduction as a key enabling technology for lowering fuel consumption in combustion engine vehicles and for extending the range-and the size- of alternative vehicles. It is known that the amount of electricity needed to power an electric vehicle is mostly driven by vehicle weight. The heavier the car, the bigger the battery required. Larger capacity batteries cost more and weigh more, take longer to charge, require a greater level of manufacturing capacity to produce, and increase the demand for new and expensive high voltage charging infrastructure.

Large reductions in weight are often thought of as requiring radical changes, such as all aluminum bodies, or carbon-fiber composites that are sometimes featured in concept vehicles and high end production models. Although these materials are used selectively today and are likely to see broader application in the future, it is important to be aware of the substantial, near-term opportunities from less costly available technologies utilizing engineering plastics and lightweight metals, as well as steel and iron.

The Future Steel Vehicle (FSV) Program has recently featured steel body structure designs that reduce mass by more than 35 percent over a benchmark vehicle and reduce total life cycle emissions by nearly 70 percent. The FSV program has brought more advanced steels and steel technologies to its portfolio, including more than 20 new Advanced High Strength Steels (AHSS) grades, representing materials expected to be commercially available in the 20152020 technology horizon. The FSV material portfolio includes the first generation of AHSS, i.e., steels that possess primarily ferrite-based microstructures such as dual phase (DP), transformation-induced plasticity (TRIP) [1], complex-phase (CP), and martensitic (MART) steels; and the second generation of AHSS, i.e., austenitic steels with high manganese contents, which include steels that are closely related to austenitic stainless steels, such as twinning-induced plasticity (TWIP) steels [2]. All these type of steels reach into GPa-strength levels and are the newest in steel technology offered by the global industry.

Recently, there has been increased interest in the development of the third generation of AHSS, i.e., steels with strength-ductility combinations significantly better than exhibited by the first generation AHSS, but at a cost significantly less than required for second generation AHSS. The third generation of AHSS will include materials with microstructures consisting of a high strength phase (e.g., ultra-fine grained ferrite, martensite, or bainite) and a significant amount of ductile austenite that improves the work-hardening of the complex composite structure by TRIP effect.

Approaches to the development of the third generation of AHSS have been recently performed [3-7]. A new process referred to as quenching and partitioning (Q\&P), has recently been shown to be a unique processing route for the production of high strength martensitic steels with significant amounts of retained austenite [3]. The materials are rapidly cooled to a specific quench temperature between $\mathrm{M}_{\mathrm{S}}$ and $\mathrm{M}_{\mathrm{F}}$ to create controlled fractions of martensite and austenite. This step is followed by a thermal treatment at the partitioning temperature, at which carbon migrates from martensite to austenite to increase the austenite stability resulting in higher austenite fractions at room temperature after cooling. In the Q\&P process, formation of iron carbides is intentionally suppressed, and the austenite is stabilized rather than decomposed. The sensitivity of the Q\&P process to alloy content and processing temperatures has been explored, and it has been shown that the Q\&P process works as a viable route to produce third generation AHSS in a variety of alloy systems. Of particular interest is the strength/ductility performance of a $0.2 \mathrm{C}-1.6 \mathrm{Mn}-1.6 \mathrm{Si}$ (wt.\%) alloy processed with Q\&P heat treatment [4]. 
Alternatively, design methodologies based on diffusionless bainite transformation theory have been applied to develop steels with a carbide-free bainitic (CFB) microstructure consisting of a mixture of bainitic ferrite, retained austenite, and some martensite [5-8]. Using thermodynamics and kinetics models, CFB steels with a 0.2 and 0.3 wt.\% carbon content were designed and manufactured following a conventional hot rolling practice. The designed steels present significant combinations of strength and ductility, with tensile strengths ranging from 1300 to $1800 \mathrm{MPa}$ and total elongations of over $14 \%$.

In terms of in-use properties, first generation of AHSS, such as low alloy TRIP steels, are excellent in stretch formability due to their large uniform elongation, but they are generally inferior in stretch flangeability, as in the expansion of a pierced hole. This is related to the presence of hard and soft phases in their microstructure [9]. Although stretch flangeability is also known to decrease with increasing strength, the effect of micro-scale uniformity is noteworthy - the more uniform the microstructure, the better the stretch flangeability. Bendability can also be construed to be similar to stretch flangeability, as a fracture due to a large local deformation [10], and can be adjusted, for example, by the scatter of hardness (i.e., the distribution of hard and soft phases in the microstructure) for $980 \mathrm{MPa}$-class steel. Accordingly, the improvement of bendability can be achieved by the same concept as in the improvement of stretch flangeability.

These weak points corresponding to the formability of first generation of AHSS may be overcome by replacing the polygonal ferrite matrix in TRIP steels by a lath-like ferrite matrix [11]. The CFB steel is expected to achieve extremely good stretch-flangeability due to its uniform fine lath structure. On the other hand, the heterogeneities of hardness due to the presence of martensite in this advanced bainitic microstructure will allow this steel to reach a good, deep drawability [12]. In this sense, the main objective of this work is to design cold rolled and continuous annealed AHSS with a CFB microstructure for manufacturing of uncoated (i.e. bare) or electrogalvanized (EG) products for the automotive industry, overcoming property limitations of AHSS commercially available for cold-stamping or coldforming products. In more detail, the engineering requirements are for an ultimate tensile strength (UTS) higher than $1000 \mathrm{MPa}$, a yield stress/ultimate tensile stress (YS/UTS) ratio of 0.7, a combination of strength and total elongation (UTSxTEl) higher than 15,000 $\mathrm{MPa} \%$, and a hole expansion (HE) ratio higher than 30\%. The sufficiently tough matrix and the control of the heterogeneity in the microstructure will enable an optimal ductility that is comparable to drawing steels while keeping a suitable bending performance.

\section{Theoretical Calculations and Alloy Design}

An alloy design procedure [5] based on phase transformation theory alone was successfully applied to design steels with a CFB microstructure. An increase in the amount of bainitic ferrite is needed in order to avoid the presence of large regions of untransformed austenite, which under stress, decompose to brittle martensite.

\subsection{Outline of phase transformation models in steels}

The bainite transformation progresses by the diffusionless growth of tiny platelets known as 'sub-units' [13]. The excess carbon in these platelets partitions into the residual austenite soon after the growth event. Diffusionless growth of this kind can only occur if the carbon concentration of the residual austenite is below that given by the $T_{0}$ curve. The $T_{0}$ curve is the locus of all points, on a temperature versus carbon concentration plot, where austenite and ferrite of the same chemical composition have the same free energy [14]. It follows that the 
maximum amount of bainite that can be obtained at any temperature is limited by the fact that the carbon content of the residual austenite must not exceed the $T_{0}$ curve of the phase diagram. The design procedure avoids this difficulty in two ways: by adjusting the $T_{0}$ curve to greater carbon concentrations with the use of substitutional solutes such as $\mathrm{Mn}$ and $\mathrm{Cr}$ and by controlling the mean carbon concentration $[15,16]$.

Bainite is formed below the $\mathrm{T}_{\mathrm{o}}$ temperature when $\Delta G^{\gamma \rightarrow \alpha}<-G_{S B}$ and $\Delta G_{m}<G_{N}$, where $G_{S B} \cong 400 \mathrm{~J} \mathrm{~mol}^{-1}$ is the stored energy of bainite [14] and $\Delta G^{\gamma \rightarrow \alpha}$ is the free energy change accompanying the transformation of austenite without any change in chemical composition. The first condition therefore describes the limit to bainite growth. The second condition refers to nucleation; thus, $\Delta G_{m}$ is the maximum molar Gibbs free energy change accompanying the nucleation of bainite. $G_{N}$ is a universal nucleation function based on a dislocation mechanism of the kind associated with martensite [17]. The temperature dependence of $G_{N}$ is independent of chemical composition; together with the growth condition, the function allows the calculation of the bainite start temperature, $\mathrm{B}_{\mathrm{S}}$, from a knowledge of thermodynamics alone.

Apart from controlling the $\mathrm{T}_{\mathrm{o}}$ curve and $\mathrm{B}_{\mathrm{S}}$ temperature, substitutional solutes also affect hardenability, which is an important design parameter to avoid transformations such as proeutectoid ferrite and pearlite. For this purpose, thermodynamic and kinetics models developed to allow the estimation of isothermal and continuous transformation diagrams, from the knowledge of the chemical composition of the steel concerned, were used in the alloy design process [18-22]. There are other output parameters, such as the martensite and Widmanstätten start temperatures. An extensive description of all the models used on the design procedure was reported elsewhere [5].

\subsection{Earlier developments of CFB steels}

Edmonds and co-workers [15,16,23-25] showed that CFB is, in principle, an ideal microstructure from many points of view. An example of the microstructure of CFB is presented in Fig. 1; instead of the classical structure of bainitic ferrite laths with interlath carbide, it consists of bainitic ferrite laths interwoven with thin films of untransformed retained austenite. In particular, the steel has a high resistance to cleavage fracture and void formation due to the absence of fine carbides. There is a possibility of simultaneously improving the strength and toughness because of the ultrafine grain size of the bainitic ferrite plates, and of further enhancing the ductility by TRIP effect. Original experiments by Bhadeshia and Edmonds [15,16] were carried out in order to demonstrate the role of the $T_{0}$ curve in greatly influencing the mechanical properties of carbide-free bainitic steels. The experimental alloys developed for this purpose were not necessarily the optimum alloys from the point of view of mechanical properties.

Caballero et al. [26,27] used a combination of the models mentioned above to design alloys with enough hardenability to obtain a full bainitic microstructure after forging and air cooling. The alloys contained 3.5Ni-1.4Cr-(0-0.1)V (wt.\%) for hardenability, $1.5 \mathrm{wt} . \%$ Si to prevent the precipitation of cementite during bainite formation, and $0.25 \mathrm{wt} . \%$ Mo to prevent temper embrittlement due to $\mathrm{P}$ in the alloy. In order to reach high strength (1100 MPa as minimum), the amount of carbon was selected to be $0.3 \mathrm{wt} . \% \mathrm{C}$ in the two designed alloys. Designed steels were forged to a thickness of $25 \mathrm{~mm}$ before their temperature fell below $750{ }^{\circ} \mathrm{C}$ and air cooled. Microstructural characterization revealed that the Ni alloyed steels had the desired microstructure consisting of bainitic ferrite and interlath high carbon ( $\sim$ wt.\% C) retained austenite films [27]. The two steels achieved toughness values of nearly $130 \mathrm{MPa} \mathrm{m}^{1 / 2}$ and strength in the range of 1500-1700 MPa [27,28]. 
More recently [5-7], Fe-(0.2-0.3)C-1.5Si-(1.5-2.3)Mn-(0-1.5)Ni-(0-1.5)Cr-0.2Mo (wt.\%) alloys were designed to obtain a full bainitic microstructure after hot rolling and a two-step cooling schedule. After finishing rolling, a rapid cooling was performed to avoid the formation of proeutectoid ferrite during cooling, and before the $\mathrm{B}_{\mathrm{S}}$ temperature is reached, the cooling rate was decreased in order to cross the bainitic region of the time-temperature transformation (TTT) diagram. The designed alloys were hot rolled to $\sim 12 \mathrm{~mm}$ in several passes finishing at $\sim 915{ }^{\circ} \mathrm{C}$. The desired CFB microstructure was obtained in all the steels by air cooling from different temperatures $\left(450-600^{\circ} \mathrm{C}\right)$ after an initial accelerated cooling at $\sim 60$ ${ }^{\circ} \mathrm{C} / \mathrm{s}$. The combination of strength and ductility reached by these steels (UTSxTEl up to 30,000 MPa\%) was higher than those in ferritic TRIP steels (typically 22,500 MPa\%) [29]. Moreover, the YS/UTS ratio was as low as those obtained in DP steels, which can be beneficial for drawability.

\subsection{Alloy Design of Annealed Cold Rolled Carbide-Free Bainitic Steels}

Bearing in mind the continuous annealing line (CAL) for commercial manufacturing of bare or EG products, the chemical composition of the new alloys has to be adapted in order to ensure a low $\mathrm{Ac}_{3}$ temperature to guarantee full austenitization during annealing and sufficient hardenability to avoid proeutectoid ferrite upon cooling after annealing.

The base alloy system Fe-(0.15-0.3)C-1.5Si-Mn-Cr (wt.\%) was proposed to fulfill these engineering requirements. As mentioned above, Si avoids cementite precipitation during bainite formation; however, the use of a high Si content can be challenging regarding final surface quality product. Although the partial replacement of Si by Al could overcome this problem, thermodynamics calculations confirmed that the use of $\mathrm{Al}$, a strong ferrite former element, is not a viable option to accomplish the criterion of low $\mathrm{Ac}_{3}$ temperature. On the other hand, different carbon content (0.15-0.3 wt.\%) were proposed with the aim of exploring the development of weldable bainitic steels. The addition of expensive Mo was avoided, and its substitution by $\mathrm{Cr}$ was proposed, in comparison to former approaches [5-7]. Finally, addition of $\mathrm{Cu}$ and $\mathrm{Ni}$ was considered in order to study the role of austenite former elements on CFB microstructures [30], taking into account that tensile elongation in these steels is mainly controlled by the amount of retained austenite.

our strategy was also to suppress?

According to thermodynamics calculations on the carbon content of the residual austenite at a given temperature of $400{ }^{\circ} \mathrm{C}$, shown in Fig. 2.a for the base alloy system Fe-0.3C-1.5Si-Mn$0.6 \mathrm{Cr}$ (wt.\%), a Mn content of $\sim 2 \mathrm{wt} . \%$ is recommended to get a bainitic steel with the same $\mathrm{T}_{0}$ line than that achieved in earlier developed CFB steels [7]. Likewise, calculations suggested that the $\mathrm{Mn}$ alloy content should be reduced to reach the same $\mathrm{T}_{\mathrm{o}}$ line criterion if $\mathrm{Cu}$ and $\mathrm{Ni}$ are used as alloying elements.

The maximum volume fraction of bainite, $\mathrm{V}_{\mathrm{B} \text {-max }}$, which can be formed at a given temperature is directly related to the $T_{0}$ curve and can be calculated with the following equation:

$V_{B-\max }=\frac{\left(x_{\gamma}-x\right)}{\left(x_{\gamma}-s\right)}$,

where $x_{\gamma}$ is the carbon content of austenite according to the $\mathrm{T}_{0}$ curve, $\bar{x}$ is the average carbon content of the alloy, and $s$ is the amount of carbon trapped in the bainitic ferrite in solid solution ( $s=0.03 \mathrm{wt} . \%$ ). Besides the independence of the $\mathrm{T}_{\mathrm{o}}$ curve with the average carbon content of the steel [14], the maximum volume fraction of bainite formed at a given transformation temperature will increase as the carbon content of the steel is decreased since 
the critical carbon concentration for displacive transformation is reached at a later stage $[15,16]$.

Additional calculations on the carbon content of the residual austenite at $400{ }^{\circ} \mathrm{C}$, shown in Fig. 2.b for the alloy system Fe-C-1.5Si-Mn-Cr (wt.\%), allowed designing a batch of alloys with different carbon content (0.15-0.25 wt.\%) and different Mn additions (1-2.5 wt.\%) that can achieve the same amount of bainite than observed in earlier developed CFB steels [7] after completion of the transformation. Horizontal lines in Fig. 2.b correspond to the required carbon content in austenite at $400{ }^{\circ} \mathrm{C}$ to reach the $\mathrm{V}_{\mathrm{B} \text {-max }}$ of the reference steels [7] for different average carbon contents $(0.3,0.25,0.2$, and $0.15 \mathrm{wt} . \%)$. It is clear that reducing the carbon content at higher alloying additions of $\mathrm{Mn}$ and $\mathrm{Cr}$ are needed to fulfill the maximum volume fraction of bainite criterion.

The chemical composition of the proposed alloys for the manufacturing of cold rolled and continuous annealed bainitic steels are listed in Table 1. Alloys CR1-CR4 were selected to explore the effect of carbon content on the development of high Mn (2 and 2.5 wt.\%) bainitic steels, whereas CR5-CR7 were designed to study the effect of austenite former elements, such as $\mathrm{Cu}$ and $\mathrm{Ni}$, in low $\mathrm{Mn}$ (1.5 wt.\%) bainitic steels. The different combinations of $\mathrm{Mn}$ and $\mathrm{Cr}$ contents were selected following thermodynamics calculations shown in Fig. 2.

\section{Materials and Heat Treatment Simulations}

Seven ingots of the designed compositions for cold rolled and annealed bainitic steel (CR1CR7) were cast using a vacuum induction melting furnace. Their actual composition is listed in Table 1. The $\mathrm{P}$ and $\mathrm{S}$ contents are representative of an industrial production in order to test the mechanical properties of the designed steels in the continuous annealed condition. All the ingots were hot rolled to a thickness of $3 \mathrm{~mm}$ following the thermomechanical control process of commercial SiMn TRIP steels described in Fig. 3.a. A high coiling temperature of $550{ }^{\circ} \mathrm{C}$ was selected to trigger the ferrite-pearlite transformation region, and thus, to achieve soft hot rolled strips and to enable the cold-rolling without limiting the accessible gauge thickness for the final product. Considering the high Si content of the designed steels, higher coiling temperatures are not recommended for preventing inter-granular oxidation, which could cause the deterioration of product performance [31]. The low hardness of the hot rolled strips (below $400 \mathrm{HV}$ ) enabled the subsequent cold rolling of the material without any further softening treatment. All the strips were cold-rolled to a total reduction rate of $50 \%$ in multiple passes, without any cracks.

\subsection{Continuous Annealing Simulations}

A scheme of the temperature-time profile used during the continuous annealing process for commercial manufacturing of bare or EG products is illustrated in Fig. 3.b. Before heat treatment simulation, critical transformation temperatures, $\mathrm{Ac}_{1}$ and $\mathrm{Ac}_{3}$, and the $\mathrm{M}_{\mathrm{S}}$ transformation temperature after austenitization at $890{ }^{\circ} \mathrm{C}$ for $100 \mathrm{~s}$ and subsequent quenching, were experimentally determined by means of an Adamel Lhomargy DT1000 highresolution dilatometer [32] in the designed steels. Dilatometric data in Table 2 shows that an industrial annealing temperature of $890{ }^{\circ} \mathrm{C}$ implies complete austenitization of all materials, except for CR1 steel, whose $\mathrm{Ac}_{3}$ temperature is a few degrees higher $\left(\mathrm{Ac}_{3}=895^{\circ} \mathrm{C}\right)$. Metallographic examination by scanning electronic microscopy (SEM) of the corresponding as-quenched sample revealed the presence of a minute quantity of intercritical ferrite. Moreover, preliminary dilatometric analysis of austenite decomposition at different 
temperatures (500-300 ${ }^{\circ} \mathrm{C}$ ) enabled the determination of the time necessary to finish bainitic transformation for all grades with an austenitization temperature of $890{ }^{\circ} \mathrm{C}$.

During the isothermal holding stage, between $500-300{ }^{\circ} \mathrm{C}$, of the continuous annealing process (Fig. 3.b) the austenite decomposes to bainite at temperatures above or below the $\mathrm{M}_{\mathrm{S}}$ temperature of the different designed steels (see data in Table 2). Radcliffe and Rollason [33] primarily investigated bainite formation just above $\mathrm{M}_{\mathrm{S}}$, but they also stated that a more rapid onset of the bainite reaction at temperatures below $\mathrm{M}_{\mathrm{S}}$ is a well established phenomenon and is associated with the accelerating effect of the presence of martensite plates on the nucleation of bainite in adjacent regions of untransformed austenite. The times required to finish bainitic transformation at temperatures above and below $\mathrm{M}_{\mathrm{S}}$ temperature are given in Table 3 and Fig. 4.a. The hardness values of the resulting microstructures are shown in Fig. 4.b. All these microstructures are different combinations of bainitic ferrite, retained austenite and martensite. The complexity of the microstructure does not allow distinguishing between martensite formed before bainite transformation temperature is reached and martensite formed during quenching after bainite isothermal holding. However, the former can be estimated using Koistenen-Marburger equation [34]. Kinetics results suggested that at temperatures close to $\mathrm{M}_{\mathrm{S}}$ bainite transformation, the kinetics slightly increase as Radcliffe and Rollason suggested.

To mimic the thermal profile of CAL including an overageing plateau (bare or EG products), samples were annealed by successive salt-bath treatments at different temperatures. These treatments perfect isothermal transformations and good thermal homogeneity on the strips. The annealing temperature was set at $890{ }^{\circ} \mathrm{C}$ (duration $=100 \mathrm{~s}$ ) to guarantee an austenitic soaking. The strips were then dipped into another bath at lower temperatures, bainite holding temperature (BHT) in Table 4, to enable the bainitic transformation. After a certain time, the samples were then quenched into water to stop the bainitic transformation. The tested conditions are summarized in Table 4.

\section{Microstructure and Mechanical Properties}

Examination of CAL samples using low magnification optical microscopy revealed that martensite bands were present in the microstructures of CR4, CR6, and CR7 steels (see examples in Fig. 5). The banding was more severe at the higher the BHT temperature and the lower degree of transformation. In contrast, SEM micrographs of the CAL samples showed that all the resulting microstructures are formed by a lath-like ferrite matrix, fine martensite/austenite (M/A) grains and films of retained austenite. Figure 6 shows two examples of the microstructure obtained by transformation at $400{ }^{\circ} \mathrm{C}$ ( $35{ }^{\circ} \mathrm{C}$ above the $\mathrm{M}_{\mathrm{S}}$ ) and at $350{ }^{\circ} \mathrm{C}\left(15{ }^{\circ} \mathrm{C}\right.$ below the $\mathrm{M}_{\mathrm{s}} ; \sim 15 \%$ a-thermal martensite) in CR2 steel. The lath-like ferrite matrix is a combination of bainitic ferrite and/or a-thermal martensite. Bainite is formed during bath holding and martensite is formed during quenching before bath holding if the BHT temperature is lower than the $\mathrm{M}_{\mathrm{S}}$ temperature. Subsequent precipitation of carbides in lath martensite matrix during bath holding was not evident by SEM. However, Hell et al. [8] showed evidences of self-tempering of martensite during bainite holding at $\mathrm{M}_{\mathrm{S}}-50{ }^{\circ} \mathrm{C}$ in the Fe-0.3C-2.5Mn-0.8Cr (wt.\%) alloy system.

Quantitative data on the microstructures of cold rolled steels after CAL processing are listed in Table 5. The volume fraction of martensite in bands, $V_{M}$ in matrix, was determined by a systematic manual point counting procedure in light optical micrographs at low magnification, whereas the volume fraction of $\mathrm{M} / \mathrm{A}$ constituent inside lath-like ferrite matrix was estimated by the same procedure on SEM micrographs. Quantitative X-ray diffraction analysis was used to determine the fraction of retained austenite and its carbon content. 
Retained austenite composition was calculated making use of the relationship between lattice parameter and chemical composition and assuming that during transformation only carbon diffuses.

Various mechanical tests have been carried out to study the ductility (fracture strain, total elongation) and the formability (stretching-ability related to uniform elongation, cut-edge formability, bending ability) of the studied steels. Three cylindrical tensile samples (see dimensions in Fig. 7.a) were machined from each annealed strip in the rolling direction. The tensile tests were performed at room temperature under quasi-static conditions as described in Ref. [35]. The relative reduction in area (RA) at fracture was measured post-mortem by optical microscopy (one tensile sample per condition, one measure of each part of the broken samples). This value is directly correlated to the fracture strain $\varepsilon_{\text {fracture }}$ in tension of the considered steel and is directly related to the ductility: $\varepsilon_{\text {fracture }}=\ln (1 / 1-R A)$. All the relevant parameters extracted from the tensile tests were calculated: conventional YS at $0.2 \%$ strain, UTS, uniform and total elongation (UEl and TEl, respectively) and RA at fracture. Uniform elongation is the key parameter controlling the stretching ability (in the sense of forming limit diagram, FLD), whereas reduction in area represents the ductility. The tensile tests for a given condition show good reproducibility due to the homogeneity of the thermal treatment at the scale of the strips. Moreover, hole expansion tests were carried out at a conical punch rate of 1 $\mathrm{mm} / \mathrm{s}$ in burr-up configuration to determine the hole expansion performance of the designed steels as described in Ref. [36]. The $10 \mathrm{~mm}$ diameter hole is punched in a $90 \times 90 \mathrm{~mm}^{2}$ blanks in a radial clearance of $15 \%$. During conical punching, the blank is clamped with draw beads and oiled. Only one sample was characterized for each BHT condition. The trial is stopped when the first macroscopic crack appears (length higher than half of sample thickness). The hole expansion ratio corresponds then to the relative increase in the hole diameter. Finally, Vbending tests were performed at low strain-rate to determine the maximum bending angle before fracture of the studied steels as described in Ref. [37]. The roll diameter is $30 \mathrm{~mm}$ and the trial is stopped when the applied force drops (30 N load drop) corresponding to the occurrence of the first micro-cracks. The final angle after spring back is then measured postmortem. Three samples were characterized for each tested conditions.

\subsection{Effect of Bainite Holding Temperature}

The results of the mechanical tests performed on CR1-CR7 steels are reported in Table 6 as a function of BHT conditions. All the produced microstructures show very high UTS over 1000 $\mathrm{MPa}$, even CR1 steel containing only 0.15 wt.\%C. Their total elongations are higher than $12 \%$, except CR4-400 ${ }^{\circ} \mathrm{C}$ and CR7-400 ${ }^{\circ} \mathrm{C}$, which systematically break before reaching the uniform elongation. The brittle character of both alloys is confirmed by the low RA values of CR4 steel and low HE ratio obtained with CR7 alloy. This fragile behavior is provoked by the presence of a high fraction of high-carbon martensite in the final microstructure. A significant amount of martensite is formed during cooling if a low fraction of bainite is formed at stasis of the bainite holding, as shown in Table 5. Martensitic transformation was actually apparent on dilatometric curves during the final cooling stages of CAL dilatometric trials of CR7 alloy with a BHT of $400{ }^{\circ} \mathrm{C}$. In the following, both corresponding data will thus be excluded from the analysis for readability reasons, but not neglected. In fact, this result tends to prove that too high BHT is not suitable to produce carbide-free bainitic steels.

The effect of BHT temperature on the strength, ductility, and formability of the studied steels is shown in Fig. 8. All the studied steels present very similar tensile behavior. In the studied range of BHT, UEl increases as a function of BHT, whereas UTS decreases linearly with hardness values anticipated in Fig. 4.b. The tensile performance of the designed steels is superior than results formerly reported by Sugimoto et al. [38] in Fe-(0.2-0.6)C-(1.5-2.5)Mn- 
1.5Si alloying system and in accordance with Hell et al. [8] in Fe-(0.1-0.3)C-2.5Mn-1.5Si$0.8 \mathrm{Cr}$ alloying system.

The RA value (corresponding to the fracture strain in tension) does not seem to change as a function of BHT temperature (Table 6), but the maximum bending angle and the HE ratio (cut-edge stretching ability) decrease significantly as BHT temperature increases from 300 or $350{ }^{\circ} \mathrm{C}$ up to $400{ }^{\circ} \mathrm{C}$ (Fig. 8.C and 8.d). An increase in BHT is expected to simultaneous decrease the MA constituent fraction and to increase the effective size of the microstructure and the self-tempered martensite fraction (transformation below $\mathrm{M}_{\mathrm{S}}$ ).

The combination of strength (UTS) and formability performance in the sense of the FLD (i.e. $\mathrm{UEl}$ ) of the designed alloys is shown in Fig. 9.a in comparison to results for DP steels containing 1.5 wt.\%Si [39]. In general, the alloys transformed at $400^{\circ} \mathrm{C}$ present better formability performance than those reported on DP steels. At this BHT temperature, the microstructure is composed of bainitic ferrite, films of retained austenite and MA islands. By contrast, the alloys transformed at $300{ }^{\circ} \mathrm{C}$ and/or $350{ }^{\circ} \mathrm{C}$ exhibited lower formability than that in DP steels. At 300 and $350{ }^{\circ} \mathrm{C}$ of BHT, the microstructure is mainly composed of bainitic ferrite, martensite (probably tempered), and a low fraction of retained austenite. On the other hand, the YS/UTS ratio remains roughly constant $(\sim 0.7)$, as shown in Fig. 9b, confirming results already reported [40,41].

The improved elongation of the designed steels achieved after transformation at $400{ }^{\circ} \mathrm{C}$ is clearly observed by comparing directly the tensile curves and their corresponding evolution of the instantaneous strain-hardening coefficient $\left(\mathrm{n}^{*}\right)$, defined as $\mathrm{n}^{*}=d \ln (\sigma) / d \ln (\varepsilon)=\varepsilon d \sigma / \sigma d \varepsilon$, as a function of true strain for CR2 alloy at different BHT temperatures in Fig. 10. The evolution of $n^{*}$ as a function of true strain of the microstructure formed at $400{ }^{\circ} \mathrm{C}$ shows a plateau, which can be attributed to a TRIP mechanism associated with a certain fraction of retained austenite ( 15\%). Microstructures formed at lower BHT temperatures contained lower fractions of retained austenite (8-9\%) leading to a weaker TRIP effect, but still evident by the plateau in $\mathrm{n}^{*}$ evolution even for microstructures obtained at a BHT of $350{ }^{\circ} \mathrm{C}$.

\subsection{Effect of the Chemical Composition}

The TEl x UTS performance index of the designed CAL cold rolled steels is listed in Table 6 . All the alloys present a performance index higher than 15,000 $\mathrm{MPa} \%$ and close to 20,000 $\mathrm{MPa} \%$, as reported by Kobe steel [40,41], except CR4- $400^{\circ} \mathrm{C}$ and $\mathrm{CR} 7-400^{\circ} \mathrm{C}$, which as already mentioned, systematically broke before reaching the uniform elongation. The best performance was reached by CR3 alloy transformed at $400^{\circ} \mathrm{C}$. Results suggest that the performance index TEI x UTS increases as the austenite stabilizer element $(\mathrm{C}+\mathrm{Mn}+\mathrm{Cu}+\mathrm{Ni})$ content in the alloy increases at a given BHT temperature, confirming former results by Sugimoto et al. [38]. This improvement is, for instance, more obvious when considering only CR1-CR3 alloys transformed at $400^{\circ} \mathrm{C}$ or CR5-CR7 alloys transformed at $350{ }^{\circ} \mathrm{C}$. This particular trend is, however, not respected by CR5-CR7 alloys transformed at $400{ }^{\circ} \mathrm{C}$. This could be due to an insufficient bainite fraction.

In general, the performance of the designed steels is higher than those reported by Sugimoto et al. [11] for Fe-(0.1-0.6)C-1.5Mn-1.5Si steels. This progress is certainly due to the higher Mn content (2-2.5 wt.\%Mn) of the present alloys. Sugimoto et al. [11] also showed for Fe0.2C-(1-2.5)Mn-1.5Si (wt.\%) that the higher the Mn content, the higher the performance index for a given carbon content. This work proved that the improvement of strength and elongation is possible. In fact, $\mathrm{Mn}$ and carbon stabilize higher fraction of MA islands and retained austenite for a given condition (temperature and time) for bainitic transformation. 
As CR2 and CR6 steels present similar tensile behavior and common performance independently of the BHT temperature, it seems possible to conclude that the effect of $\mathrm{Cu}$ and $\mathrm{Ni}$ is comparable to that of $\mathrm{Mn}$. In fact, as calculations in Fig. 2.a anticipated, the addition of $1.5 \mathrm{Mn}+1 \mathrm{Cu}+1 \mathrm{Ni}$ (wt.\%) seems to be equivalent to $2 \mathrm{wt} . \% \mathrm{Mn}$ for the final properties. Nevertheless, $\mathrm{Cu} / \mathrm{Ni}$ additions seems to slow down the bainitic transformation at $400{ }^{\circ} \mathrm{C}(11.6$ min. for CR6 steel instead of $7.4 \mathrm{~min}$. for CR2 steel) and thus should not be recommended for industrial applications.

As discussed above, for a given composition, the RA does not seem to vary much in the studied BHT temperature range. This parameter decreases significantly, however, with the amount of alloying elements (from CR1 down to CR4. See Table 6) explained by a higher fraction of MA islands. The RA values are, however, excellent considering the UTS reached by the steels. The balance RA/UTS of the studied steels is comparable to the values reported by Sugimoto et al. [11] for Fe-0.3C-1.5Mn-1.5Si (wt.\%) for TRIP assisted steel with bainitic ferrite matrix. Moreover, damage and cracking resistance in the studied microstructures are lower than those of quenched and tempered steel containing $0.3 \mathrm{wt} . \%$ carbon reported by Krauss [42], known to be the best-in-class. This trend and positioning is consistent with the HE values reported in Fig. 8.c confirming that the higher the amount of alloying elements, the lower the resistance to damage of the microstructure (fracture strain and cut-edge sensitivity).

\subsection{Strengthening Mechanisms in Annealed Cold Rolled Bainitic Steels}

The main microstructural contribution to the strength of the achieved microstructures is from the extremely fine grain size of lath-like ferrite. It is known that the effective lath size defined by low angle boundaries explain proof strength since both lath boundaries and dislocation cell boundaries have the similar capability of being dislocation obstacles. Electron backscatter diffraction (EBSD) analysis allowed determination of the ferrite lath thickness, as reported in Fig. 11. However, present results on the lath ferrite size did not show a linear trend with the transformation temperature, explaining differences in strength for microstructures transformed over and below the Ms temperature in CR2 steel (Fig. 8.a).

Moreover, it is difficult to separate the effect of retained austenite on strength in these steels from other factors (see Fig. 12.a). Qualitatively, austenite can affect the strength in two ways: i) since austenite is a soft and ductile phase, this alone could cause a decrease in the YS; and ii) retained austenite could increase the UTS by transforming to martensite during testing, similar to the behavior of TRIP steels. Miihkinen and Edmonds [24] observed that retained austenite decreases the YS by $24 \mathrm{MPa} / \mathrm{vol} \%$. This is high compared to approx. 6-16 $\mathrm{MPa} / \mathrm{vol}$ \% measured by Sandvik and Nevalainen [43]. In the present work, retained austenite decreases the YS by $10 \mathrm{MPa} / \mathrm{vol} . \%$. On the other hand, the amount of martensite in the microstructure plays an important role on the UTS, as illustrated in Fig. 12.b.

A general observation in these steels is that YS seems to increase as the microstructure is generated at the lower temperature. As mention above, this is not explained by the lath ferrite thickness. Other strengthening mechanisms should be explored, such as possible precipitation strengthening, dislocation density, and carbon trapping at crystal defects. A carbon atom map with superimposed isoconcentration surfaces in a Fe-0.3C-2Mn-1.5Si-0.4Cr steel transformed at $350{ }^{\circ} \mathrm{C}$ for $20 \mathrm{~min}$. is shown in Fig. 13. The distribution of the carbon atoms in the analysis volume is not uniform and carbon-rich and carbon-depleted regions are clearly distinguishable. Measurements of the carbon content of the different detected features allowed for identifying the analyzed area of the needle-shaped sample as a bainitic ferrite lath $(<0.03$ wt.\% C), including various carbon-enriched clusters and an inter-lath boundary. The proximity histogram across the clusters showed a maximum carbon content ranging from 2.61.8 wt.\%, but with barely $\mathrm{Cr}$ and Mn enrichment to be identified as a carbide. These features 
resemble those carbon clusters with a modulated structure consisting of alternating carbonrich and carbon-poor bands reported for $\mathrm{Fe}-\mathrm{Ni}-\mathrm{C}$ martensite after natural ageing. It is evident from the atom maps that substitutional solutes are also segregated on the ferrite lath boundaries (see arrows designating regions in Fig. 13).

4.4 Microstructure Control of Ductility and Formability in Annealed Cold Rolled Bainitic Steels

Low YS/UTS ratios in Table 6 are known to be due to the presence of austenite [44]. Results in Fig. 14.a confirmed that UEl, controlling the stretching ability in terms of FLD, is mainly affected by the volume fraction of retained austenite, which is a ductile phase compared to the lath ferrite, and it would be expected to enhance work-hardening as far as the austenite is homogeneously distributed in the microstructure. In addition, TEl seems to be higher as the microstructure is generated at the higher temperature. Lower TEl values were caused by rapid falling-off of the strain-hardening rate in an early stage, resulting from a harder matrix with a higher dislocation density and lower strength ratio of $2^{\text {nd }}$ phase/matrix that enhances stress concentrations as Kernel maps in Fig. 15 seem to indicate. Kernel maps in Fig. 15 show the micro-strain distribution in samples transformed at different BHT temperatures for CR2 steel. Kernel maps have become a standard method for indicating small, relative differences in crystallographic orientation (angular misorientations) between neighboring points in the specimen. Often these maps provide indications of the results of elastic strain. Internal strains often show a rapid change from point to point and if they go significantly beyond the elastic limit they will typically include dislocations within the sample volume, indicated by crystal rotations and a higher value of the Kernel map [45]. Thus, results in Fig. 15 seem to confirm the existence of non-relaxed strain gradients (red points inside circles) generated by displacive transformation, which are responsible for premature failure in samples transformed below $\mathrm{M}_{\mathrm{S}}$ temperature. This indicates that softening of the lath structure matrix brings on enlargement of the total elongation. This might be an outcome of the lower strength obtained following transformation at high temperatures. Finally, it seems clear that increasing the austenite content enhances the strain-hardening rate and overall performance of the steel (Fig. 14.b), whereas the fracture strain (RA), cut-edge sensitivity (HE), and bendability (bending degree) seem to be controlled by the amount of second phases (martensite/austenite), as shown in Fig. 14.c.

\subsection{Performance of Designed Steels in Comparison to Commercial Products}

A comparison of the studied steels with more conventional high strength steels now widely used by automotive car makers (cold-stamped and cold-formed parts) [46] is presented in Fig. 16. The designed steels reach far higher uniform elongations (better stretching ability and formability considering the forming limit diagram) than that in DP980 and Martensitic 1400 steels considering the same range of ultimate tensile strengths. For instance, CR3 steel transformed at $400{ }^{\circ} \mathrm{C}$ is actually as formable as DP780 steel with far higher UTS $(+500$ $\mathrm{MPa})$. Nevertheless, the YS/UEl performances are less exceptional, but are in line with the actual products. In other words, the initial work-hardening rates of the studied steels are higher than DP980, confirming the better stretching ability.

The most remarkable comparison comes from analysis of HE performances as function of UTS of the considered steels. Due to the bainitic/self-tempered martensitic matrix, the studied steels show a very high HE ratio compared to fully martensitic steels and DP steels. As expected, due to the specific alloy design, the studied steels simultaneously exhibit a sufficient stretch-ability for cold-stamping operations and very high resistance to damage 
processes (fracture strain, cut-edge sensitivity, and bendability). Their mechanical performances are thus outstanding compared to present-day very high strength steels.

\section{Conclusions}

The designed bainitic steels for CAL lines are very promising. They present high tensile performances (UTS > $1000 \mathrm{MPa}$ ) and their properties can be adjusted for cold-stamping applications as a result of an adequate choice of the bainitic transformation temperature. However, the following constraints have been identified:

1) In order to achieve a fully austenitic soaking during annealing, the $A_{c 3}$ temperature of the design alloy should be below the highest temperature accessible by plants.

2) The critical cooling rate of the alloy should be designed sufficiently high to avoid ferrite upon cooling.

3) The bainite holding temperature is a relevant parameter to optimize formability-strength balance of the final products. Temperatures above $\mathrm{M}_{\mathrm{s}}$ and close to $400{ }^{\circ} \mathrm{C}$ should be selected to reach optimized uniformed elongation, whereas low temperature bainitic holding should be used to produce high HE products. In both cases, the expected performances are higher than those of conventional very high strength steels (i.e., DP steels). However, bainitic holding at too high temperature (i.e., $450{ }^{\circ} \mathrm{C}$ ) could lead to insufficient transformed fractions and should be avoided.

4) The control of the duration of the bainitic transformation is a key issue for the design of industrial products, highlighted by the poor properties obtained with CR4. The durations used for the laboratory sample production are for the moment incompatible with industrial capability (too long a bainitic plateau), except CR1 or CR5 alloy (300 s). Too short a bainitic holding would result in low damaging performance of the microstructure (too high fraction of fresh martensite).

5) This study confirmed that austenite stabilising elements, such as $\mathrm{C}, \mathrm{Mn}, \mathrm{Cu}$, and $\mathrm{Ni}$ significantly improve the mechanical performance of carbide-free bainitic steels. $\mathrm{Cu}$ and $\mathrm{Ni}$ seem to have the same effect as Mn and C. Nevertheless, all these elements slow down the bainitic transformation kinetic.

\section{Acknowledgements}

The authors gratefully acknowledge the support of the Research Fund for Coal and Steel and the Spanish Ministry of Science and Innovation for funding this research under the contracts RFSR-CT-2008-00021 and MAT2010-15330, respectively. J. Cornide acknowledges the Spanish Ministry of Science and Innovation for financial support in the form of a $\mathrm{PhD}$ research grant (FPI). Atom probe tomography research is supported by ORNL's Shared Research Equipment (ShaRE) User Facility, which is sponsored by the Office of Basic Energy Sciences, U.S. Department of Energy.

\section{References}

[1] Jacques PJ. Transformation-induced plasticity for high strength formable steels. Curr Opin Solid St M 2004;8:259-265. 
[2] Bouaziz O, Allain S, Scott CP, Cugy P, Barbier D. High manganese austenitic twinning induced plasticity steels: A review of the microstructure properties relationships. Curr Opin Solid St M 2011;15:141-168.

[3] Speer JG, Rizzo Assunção FC, Matlock DK, Edmonds DV. The "quenching and partitioning” process: background and recent progress. Mater Res 2005;8:417-423.

[4] Streicher AM, Speer JG, Matlock DK, De Cooman BC. Quenching and partitioning response of a Si-added TRIP sheet steel. In: J.G. Speer, editor. Int. Conf. on advanced high-strength sheet steels for automotive applications proceedings, Warrendale: AIST; 2004, p. 51-62.

[5] Caballero FG, Santofimia MJ, Capdevila C, García-Mateo C, García de Andrés C. Design of advanced bainitic steels by optimisation of TTT diagrams and $\mathrm{T}_{0}$ curves. ISIJ Int 2006;46:1479-1488.

[6] Caballero FG, García-Mateo C, Chao J, Santofimia MJ, Capdevila C, García de Andrés C. Effects of morphology and stability of retained austenite on the ductility of TRIPaided bainitic steels. ISIJ Int 2008;48:1256-1262.

[7] Caballero FG, Santofimia MJ, García-Mateo C, Chao J, García de Andrés C. Theoretical design and advanced microstructure in super high strength steels. Mater Des 2009;30:2077-2083.

[8] Hell JC, Dehmas M, Allain S, Prado JM, Hazotte A, Chateau JP. Microstructureproperties relationships in carbide-free bainitic steels. ISIJ Int 2011;51:1724-1732.

[9] Mizui M, Takechi H, Sekine T. Effects of strengthening mechanisms on fatigue damage for $600 \mathrm{MPa}$ class hot-rolled high-strength sheet steels. Tetsu-to-Hagané 1990;76:414421.

[10] Takahashi M. Material characterization at high strain rates for optimizing car body structures for crash events. Nippon Steel Tech. Rep., No 88, 2003, p. 22-26.

[11] Sugimoto K, Nakano K, Song S-M, Kashima T. Retained austenite characteristics and stretch-flangeability of high-strength low-alloy TRIP type bainitic sheet steels. ISIJ Int 2002;42:450-455.

[12] Nagasaka A, Sugimoto K, Kobayashi M, Hashimoto S. Effects of warm forming on stretch-flangeability of a TRIP-aided dual-phase sheet steel. Tetsu-to-Hagané 1997;83:335-340.

[13] Bhadeshia HKDH, Edmonds DV. The mechanism of bainite formation in steels. Acta Metall 1980;28:1265-1273.

[14] Bhadeshia HKDH. A rationalisation of shear transformations in steels. Acta Metall 1981;29:1117-1130.

[15] Bhadeshia HKDH, Edmonds DV. Bainite in silicon steels: new composition-property approach. Part1. Met Sci 1983;17:411-419.

[16] Bhadeshia HKDH, Edmonds DV. Bainite in silicon steels: new composition-property approach. Part2. Met Sci 1983;17: 420-425.

[17] García-Mateo C, Bhadeshia HKDH. Nucleation theory for high-carbon bainite. Mat Sc Eng A 2004;378A:289-292.

[18] Peet M, Bhadeshia HKDH. Program MAP_STEEL_MUCG83, Cambridge, Materials Algorithms Project. Available from: http://www.msm.cam.ac.uk/map/steel/programs/mucg83.html [Accessed 4 February 2013].

[19] Bhadeshia HKDH. A thermodynamic analysis of isothermal transformation diagrams. Met Sci 1982;16:159-165.

[20] Jones SJ, Bhadeshia HKDH. Kinetics of the simultaneous decomposition of austenite into several transformation products. Acta Metall 1997;45:2911-2920. 
[21] Parker SV. Modelling of phase transformation in hot rolled steels. $\mathrm{PhD}$ Thesis, University of Cambridge, U.K., 1997.

[22] Caballero FG, Capdevila C, García de Andrés C. Evaluation and review of simultaneous transformation model in high strength low alloy steels. Mat Sci Technol 2002;18:534540.

[23] Miihkinen VTT, Edmonds DV. Microstructural examination of two experimental highstrength bainite low-alloy steel containing silicon. Mater Sci Technol 1987;3:422-431.

[24] Miihkinen VTT, Edmonds DV. Tensile deformation of two experimental high strength bainite low-alloy steel containing silicon. Mater Sci Technol 1987;3:432-440.

[25] Miihkinen VTT, Edmonds DV. Fracture toughness of two experimental high strength bainite low-alloy steel containing silicon. Mater Sci Technol 1987;3:441-449.

[26] Caballero FG, Bhadeshia HKDH, Mawella KJA, Jones DG, Brown P. Design of novel high strength bainitic steels. Part 1. Mater Sci Technol 2001;17:512-516.

[27] Caballero FG, Bhadeshia HKDH, Mawella KJA, Jones DG, Brown P. Design of novel high strength bainitic steels. Part 2. Mater Sci Technol 2001;17: 517-522.

[28] Caballero FG, Chao J, Cornide J, García-Mateo C, Santofimia MJ, Capdevila C. Toughness deterioration in advanced high strength bainitic steels. Mat S. Eng A 2009;525A:87-95.

[29] Jacques P, Petein A, Harlet P. Improvement of mechanical properties through concurrent deformation and transformation: new steels for the 21st century. In: B.C. De Cooman, editor. Int. Conf. on TRIP-aided high strength ferrous alloys, Ghent; 2002, p. 281-285.

[30] Allain S, Iung T. Development of hot rolled copper/nickel alloyed TRIP steels with carbide-free bainitic matrix. Rev Metall 2008;105:520-530.

[31] Wise JP, Krauss G, Matlock DK. Microstructure and fatigue resistance of carburized steels. In: T. Bell, J.B. Cohen, K. Funatani, G.E. Totten, editors. Heat treating: including advances in surface engineering, an international symposium in honor of Professor Tom Bell, and Professor Jerome B. Cohen memorial symposium on residual stresses in the heat treatment industry: proceedings of the 20th conference, 9-12 October 2000, St. Louis, ASM International, 2000, p. 1152-1161.

[32] Garcia de Andres C, Caballero FG, Capdevila C, Alvarez LF. Application of dilatometric analysis to the study of solid-solid phase transformations in steels. Mater Charact 2002;48:101-111.

[33] Radcliffe SV, Rollason EC. The kinetics of the formation of bainite in high purity Fe-C alloys. J Iron Steel Inst 1959;191:56-65.

[34] Koistinen DP, Marburger RE. A general equation for austenite-martensite transformation in pure carbon steels. Acta Metall 1959;7:59-60.

[35] ISO 6892-1:2009. Metallic materials-Tensile testing-Part 1: Method of test at room temperature. International Organization for Standardization; 2009.

[36] ISO 16630:2003. Metallic materials -- Method of hole expanding test. International Organization for Standardization; 2003.

[37] ISO 24213:2008. Metallic materials-Sheet and strip-Method for springback evaluation in stretch bending. International Organization for Standardization; 2008.

[38] Sugimoto K, Tsunezawa M, Hojo T, Ikeda S. Ductility of 0.1-0.6C-1.5Si-1.5Mn ultra high-strength TRIP-aided sheet steels with bainitic ferrite matrix. ISIJ Int 2004;44:16081614.

[39] Matlock D, Speer J. Constitutive behavior of high strength multiphase sheet steels under high strain rate deformation conditions. AISI/DOE Project 9904, Ref. DE-FC3697ID13554, 2005.

[40] Kobe Steel. Ultra high strength steel sheet. Patent WO.2007.077933. 
[41] Kobe Steel. High strength steel sheet excellent in stretchability, stretch flangeability and weldability. Patent WO.2007.142196.

[42] Krauss G. Martensite in steel: strength and structure. Mat. Sci. Eng A 1999;273-275:4057.

[43] Sandvik BPJ, Nevalainen HP. Structure-property relationship in commercial low-alloy bainitic-austenitic steel with high strength, ductility and toughness. Met Technol 1981;15:213-220.

[44] Coldren AP, Cryderman RL, Semchysen M. Steel strengthening mechanisms. Ann Arbor, Climax Molybdenum, 1969, p. 17.

[45] Kubin LP, Mortensen A. Geometrically necessary dislocations and strain-gradient plasticity: a few critical issues. Scr Mater 2003;48:119-125.

[46] Sadagopan S, Urban D. Formability characterization of a new generation of high strength steels. DOE report No. DE-FC07-97ID13554, 2003. 


\section{Table Captions:}

Table 1: Chemical composition of cold rolled and continuous annealed carbide-free bainitic steels (wt.\%).

Table 2: Experimental critical temperatures $\mathrm{Ac}_{1}, \mathrm{Ac}_{3}$ and $\mathrm{M}_{\mathrm{S}}$ of designed steels.

Table 3: Time needed to finish bainitic transformation at temperatures above and below $\mathrm{M}_{\mathrm{S}}$ temperature.

Table 4: Parameters for CAL simulation of cold rolled bainitic steels.

Table 5: Quantitative data on microstructures formed after CAL simulation of cold rolled bainitic steels.

Table 6: Mechanical properties of cold rolled bainitic steels after CAL process. 


\section{Figure Captions:}

Figure 1.- (a) Scanning and (b) transmission electron micrographs of carbide-free bainitic microstructure. $\mathrm{M} / \mathrm{A}$ is martensite/austenite constituent; B is bainite; $\alpha_{\mathrm{b}}$ is bainitic ferrite and $\gamma$ is retained austenite.

Figure 2.- (a) Effect of Mn content on the $\mathrm{T}_{\mathrm{o}}$ curve of the alloy system Fe-C-1.5Si-Mn-0.6Cr with and without $\mathrm{Cu}$ and $\mathrm{Ni}$ additions; (b) Effect of $\mathrm{Cr}$ content on the $\mathrm{T}_{\mathrm{o}}$ curve of the alloy system Fe-C-1.5Si-(1-2.5)Mn-XCr. Horizontal lines correspond to the required carbon content in austenite at $400{ }^{\circ} \mathrm{C}$ to reach the same maximum volume fraction of bainite than that in earlier developed CFB steels [7] for different average carbon contents (0.15-0.3 wt.\%). Note that steels with different carbon content will exhibit the same $T_{0}$ curve and the maximum volume fraction of bainite formed at a given transformation temperature will increase as carbon content of the steel since the critical carbon concentration for displacive transformation is reached at a later stage [7].

Figure 3.- Scheme of temperature-time profile used for the simulation of (a) hot rolling and (b) continuous annealing processes. FRT stands for finishing rolling temperature.

Figure 4.- (a) Time to complete bainitic reaction and (b) Vickers hardness results of bainitic microstructures obtained by transformation at different temperatures in CR1-CR4 steels. Horizontal lines in (a) represent the corresponding experimental $M_{s}$ temperatures; Horizontal lines in (b) represent the hardness of the as-quenched microstructures.

Figure 5.- Optical micrographs of longitudinal CAL samples transformed at different BHT temperatures in CR7 steel: (a) $400^{\circ} \mathrm{C}$; (b) $350^{\circ} \mathrm{C}$ and (c) $300^{\circ} \mathrm{C} . \mathrm{M}_{\mathrm{S}}=300^{\circ} \mathrm{C}$. Light-etching area is martensite in bands.

Figure 6.- Scanning electron micrographs of bainitic microstructure obtained by transformation at (a) $400^{\circ} \mathrm{C}$ and (b) $350^{\circ} \mathrm{C}$ in $\mathrm{CR} 2$ steel. $\mathrm{M}_{\mathrm{S}}=365^{\circ} \mathrm{C} . \mathrm{M} / \mathrm{A}$ is martensite/austenite constituent; $\gamma$ is austenite.

Figure 7.- Non-normalized cylindrical samples used for tensile tests of CAL samples.

Figure 8.- (a) Strength, (b) elongation, (c) hole expansion (HE) ratio, and (d) maximum bending angle before fracture, of cold rolled bainitic steels after CAL process as a function of bainite holding temperature (BHT). YS is yield strength; UTS is ultimate tensile strength; UEl and TEl is uniform and total elongation, respectively.

Figure 9.- (a) The combination of strength (UTS) and formability performance in the sense of the FLD (i.e. UEl) of cold rolled bainitic steels after CAL process in comparison to results for DP steels containing $1.5 \mathrm{wt} . \%$ Si [39]; (b) YS/UTS ratio of cold rolled bainitic steels after CAL process. BHT is bainite holding temperature.

Figure 10.- (a) Engineering tensile curves of CR2 alloy after CAL at different BHT temperatures. (b) Corresponding evolution of instantaneous strain-hardening coefficient as a function of true strain. The straight line represents the instability criterion $\left(\varepsilon=n^{*}\right)$. 
Figure 11.- Orientation imaging map, misorientation map (tolerance angle of $10^{\circ}$ for high angle boundaries and tolerance angle of $2^{\circ}$ for low angle boundaries) and corresponding misorientation frequency graph of lath-like ferrite matrix in annealed CR2 steel at different bainite holding temperatures: (a) $400{ }^{\circ} \mathrm{C}$; (b) $350{ }^{\circ} \mathrm{C}$ and (c) $300{ }^{\circ} \mathrm{C}$ measured by EBSD with a $0.1 \mu \mathrm{m}$ step size;. (d) Ferrite lath thickness distribution and corresponding average values as a function of transformation temperature.

Figure 12.- Effect of (a) retained austenite and (b) martensite on strength of annealed cold rolled steels. Hollow symbols correspond to samples transformed below Ms temperature.

Figure 13.- Carbon isoconcentration surfaces at $1 \mathrm{wt} . \% \mathrm{C}$ superimposed with the carbon atom map, and solute atom maps showing carbon clusters in bainitic ferrite and solute segregation on inter-lath boundary in a steel Fe-0.3C-2Mn-1.5Si-0.4Cr (wt.\%) transformed at $350{ }^{\circ} \mathrm{C}$ for 20 min.

Figure 14.- Effect of retained austenite on (a) elongations, (b) YS/UTS ratio, and (c) reduction of area and formability performance (HE ratio and maximum bending degree) of annealed cold rolled bainitic steels. Hollow symbols correspond to samples transformed below Ms temperature.

Figure 15.- Kernel maps and corresponding local misorientation distribution of lath-like ferrite measured by EBSD with a $0.1 \mu \mathrm{m}$ step size in annealed CR2 steel at different overaging temperatures: (a) $400{ }^{\circ} \mathrm{C}$; (b) $350{ }^{\circ} \mathrm{C}$ and (c) $300{ }^{\circ} \mathrm{C}$.

Figure 16.- Performances of designed annealed cold rolled steels compared to high strength steels commercially available for cold-stamping or cold-forming products: (a) UEl and (b) HE ratio as a function of UTS. 

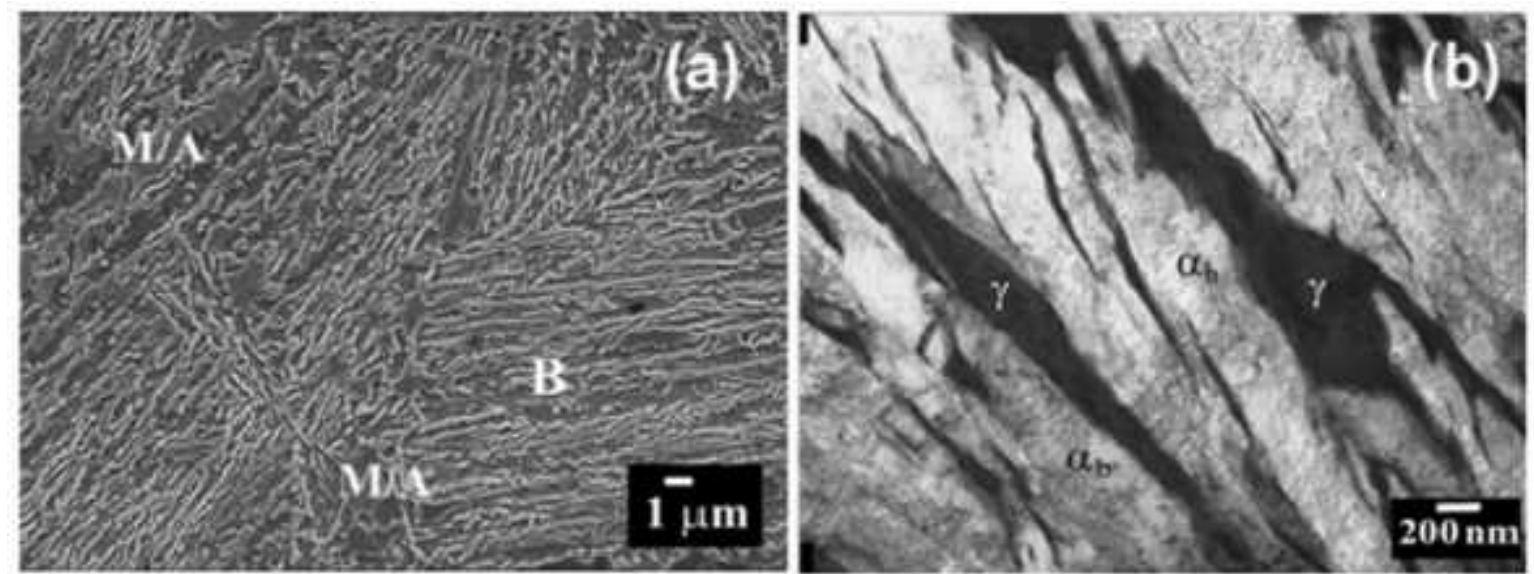

Figure 1.- (a) Scanning and (b) transmission electron micrographs of carbide-free bainitic microstructure. M/A is martensite/austenite constituent; $B$ is bainite; $\alpha_{b}$ is bainitic ferrite and $\gamma$ is retained austenite. 

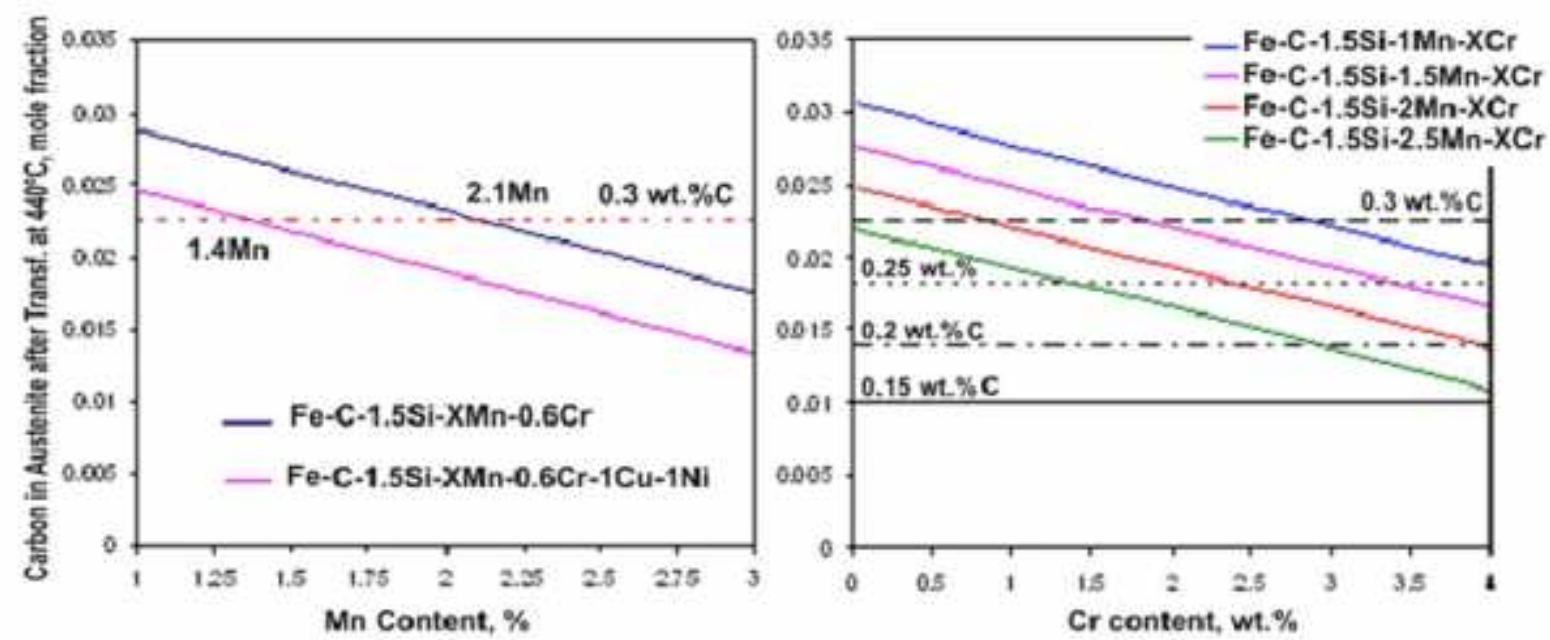

Figure 2.- (a) Effect of $\mathrm{Mn}$ content on the $\mathrm{T}_{\mathrm{o}}$ curve of the alloy system $\mathrm{Fe}-\mathrm{C}-1.5 \mathrm{Si}-\mathrm{Mn}-0.6 \mathrm{Cr}$ with and without $\mathrm{Cu}$ and $\mathrm{Ni}$ additions; (b) Effect of $\mathrm{Cr}$ content on the $\mathrm{T}_{\mathrm{o}}$ curve of the alloy system $\mathrm{Fe}-\mathrm{C}-1.5 \mathrm{Si}-(1-2.5) \mathrm{Mn}-\mathrm{XCr}$. Horizontal lines correspond to the required carbon content in austenite at $400{ }^{\circ} \mathrm{C}$ to reach the same maximum volume fraction of bainite than that in earlier developed CFB steels [7] for different average carbon contents (0.15-0.3 wt.\%). Note that steels with different carbon content will exhibit the same $\mathrm{T}_{\mathrm{o}}$ curve and the maximum volume fraction of bainite formed at a given transformation temperature will increase as carbon content of the steel since the critical carbon concentration for displacive transformation is reached at a later stage [7]. 


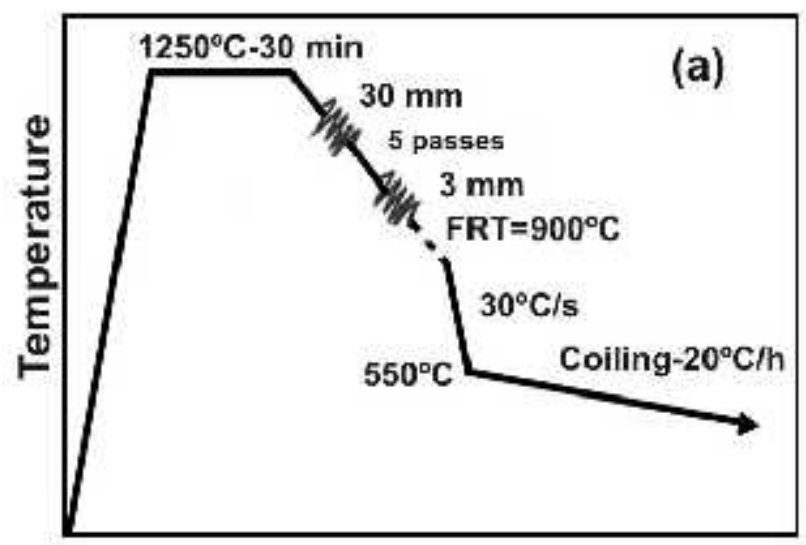

Time

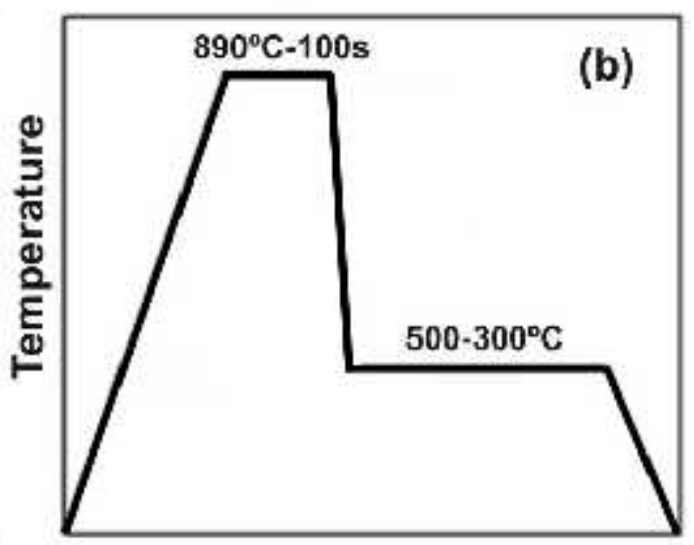

Time

Figure 3.- Scheme of temperature-time profile used for the simulation of (a) hot rolling and (b) continuous annealing processes. FRT stands for finishing rolling temperature. 

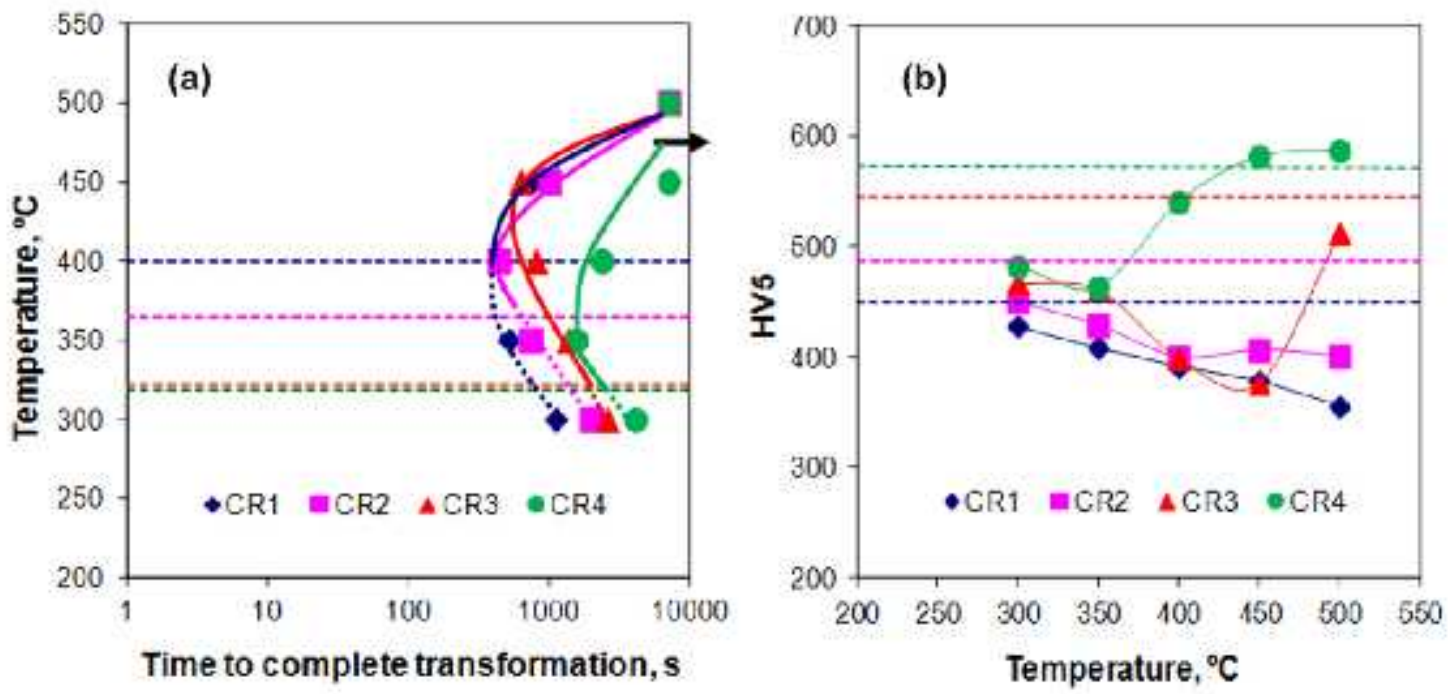

Figure 4.- (a) Time to complete bainitic reaction and (b) Vickers hardness results of bainitic microstructures obtained by transformation at different temperatures in CR1CR4 steels. Horizontal lines in (a) represent the corresponding experimental $M_{s}$ temperatures; Horizontal lines in (b) represent the hardness of the as-quenched microstructures. 

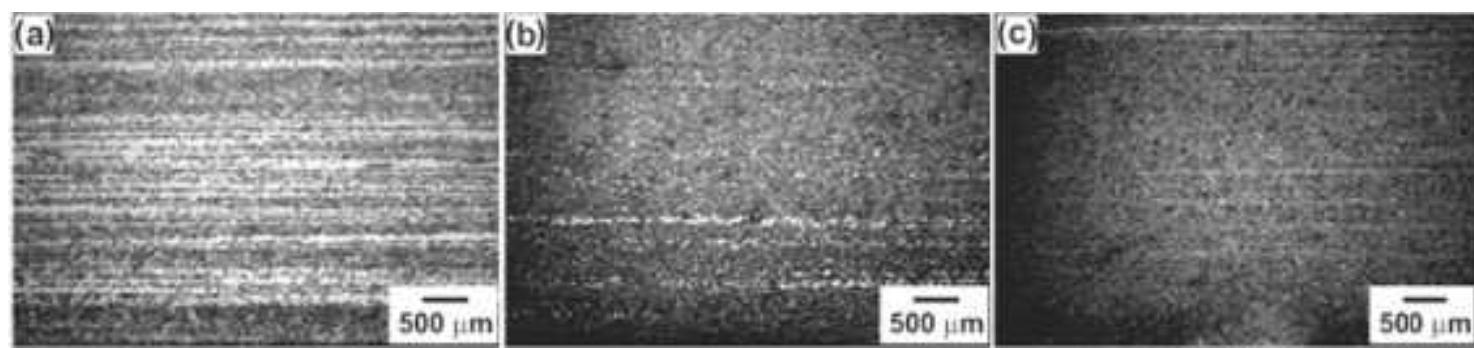

Figure 5.- Optical micrographs of longitudinal CAL samples transformed at different $\mathrm{BHT}$ temperatures in CR7 steel: (a) $400^{\circ} \mathrm{C}$; (b) $350^{\circ} \mathrm{C}$ and (c) $300^{\circ} \mathrm{C} \cdot \mathrm{M}_{\mathrm{S}}=300^{\circ} \mathrm{C}$. Light-etching area is martensite in bands. 

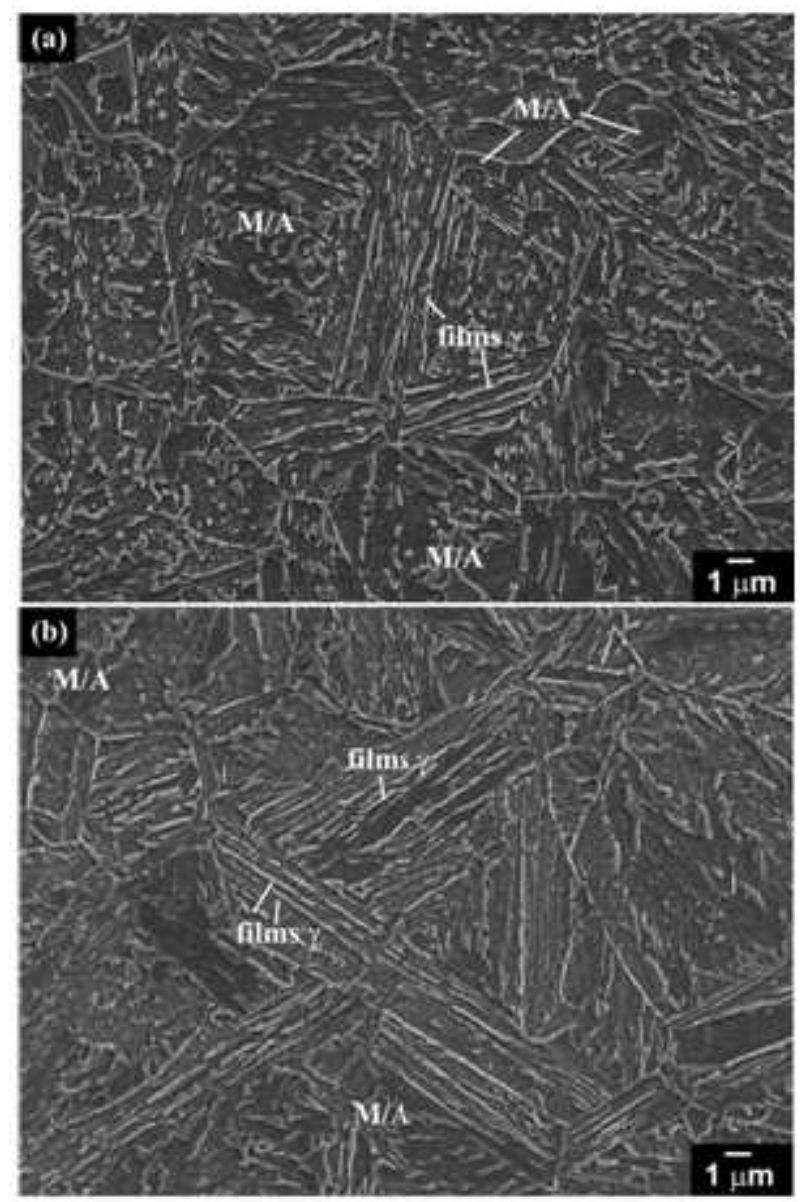

Figure 6.- Scanning electron micrographs of bainitic microstructure obtained by transformation at (a) $400^{\circ} \mathrm{C}$ and (b) $350^{\circ} \mathrm{C}$ in CR2 steel. $\mathrm{M}_{\mathrm{S}}=365^{\circ} \mathrm{C} . \mathrm{M} / \mathrm{A}$ is martensite/austenite constituent; $\gamma$ is austenite. 


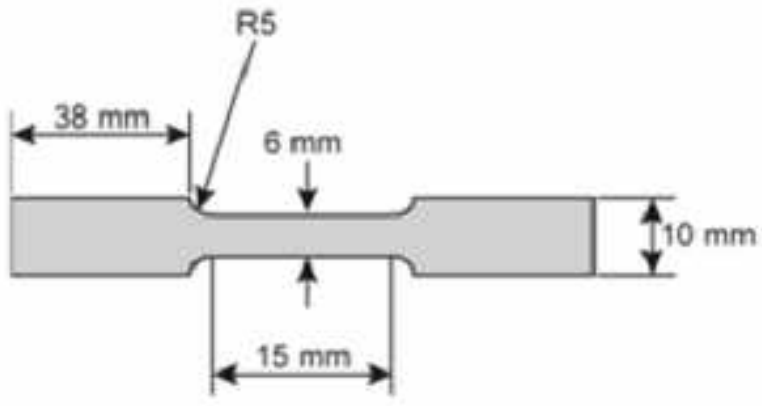

Figure 7.- Non-normalized samples used for tensile tests of CAL samples. 

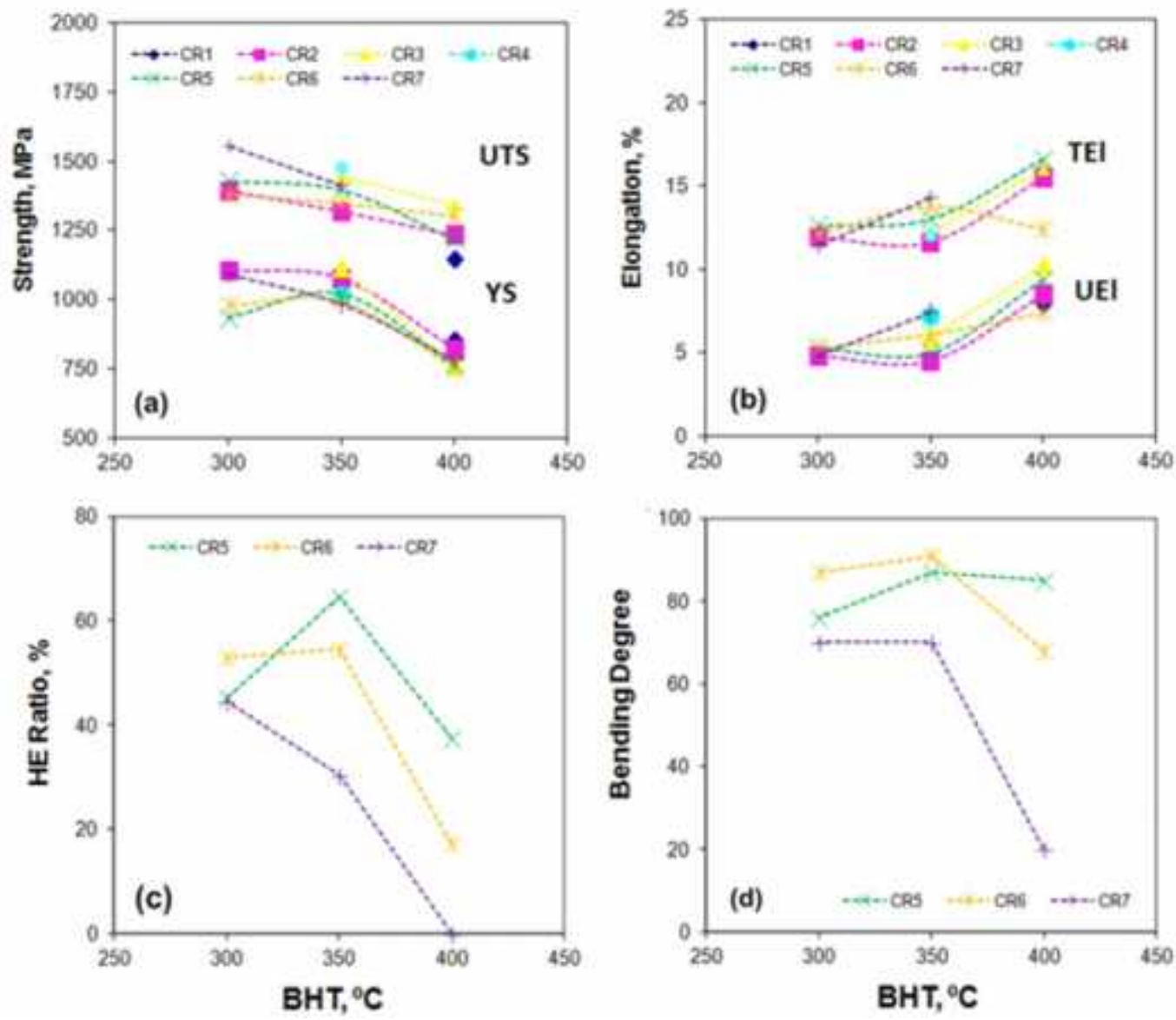

Figure 8.- (a) Strength, (b) elongation, (c) hole expansion (HE) ratio, and (d) maximum bending angle before fracture, of cold rolled bainitic steels after CAL process as a function of bainite holding temperature (BHT). YS is yield strength; UTS is ultimate tensile strength; UEl and TEl is uniform and total elongation, respectively. 

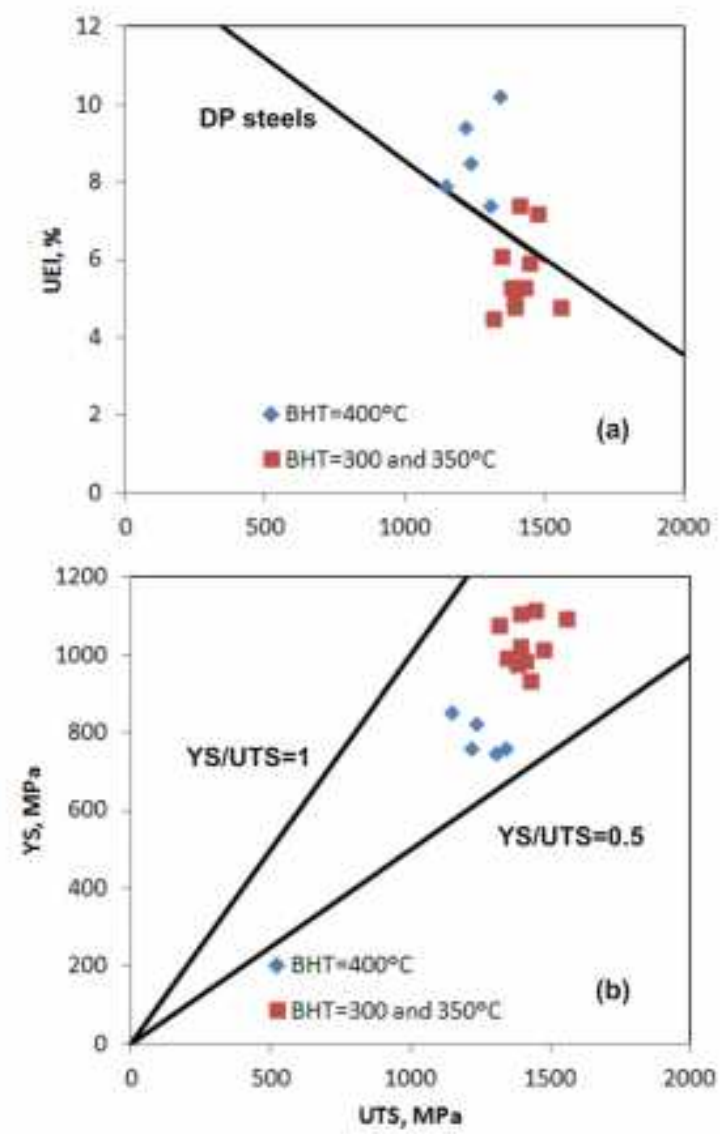

Figure 9.- (a) The combination of strength (UTS) and formability performance in the sense of the FLD (i.e. UEl) of cold rolled bainitic steels after CAL process in comparison to results for DP steels containing $1.5 \mathrm{wt} . \% \mathrm{Si}$ [39]; (b) YS/UTS ratio of cold rolled bainitic steels after CAL process. BHT is bainite holding temperature. 

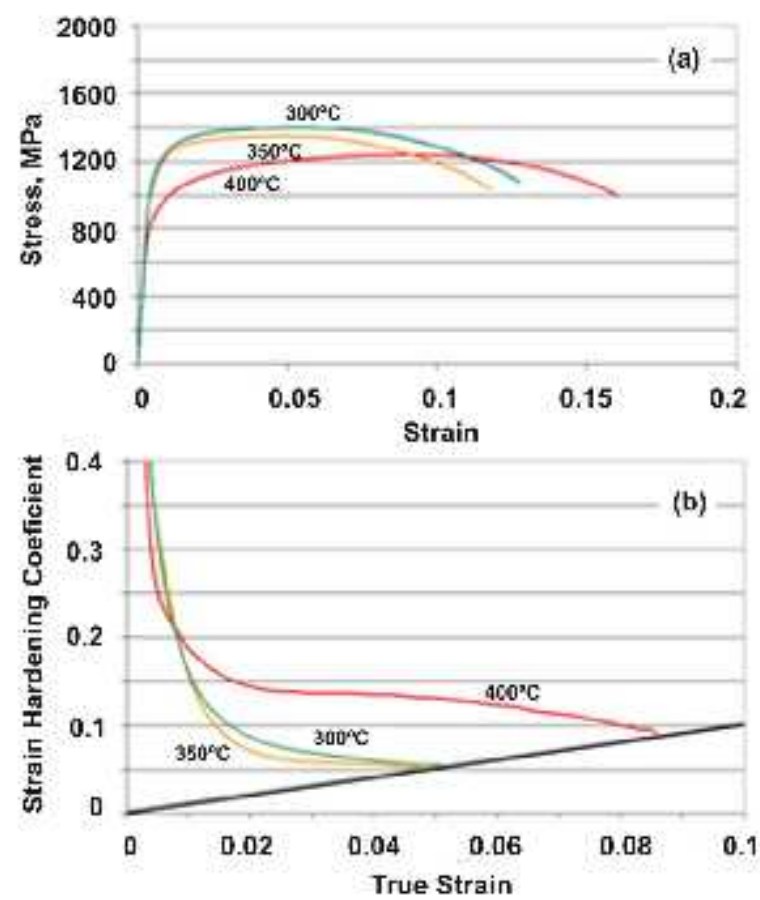

Figure 10.- (a) Engineering tensile curves of CR2 alloy after CAL at different BHT temperatures. (b) Corresponding evolution of instantaneous strainhardening coefficient as a function of true strain. The straight line represents the instability criterion $\left(\varepsilon=n^{*}\right)$. 

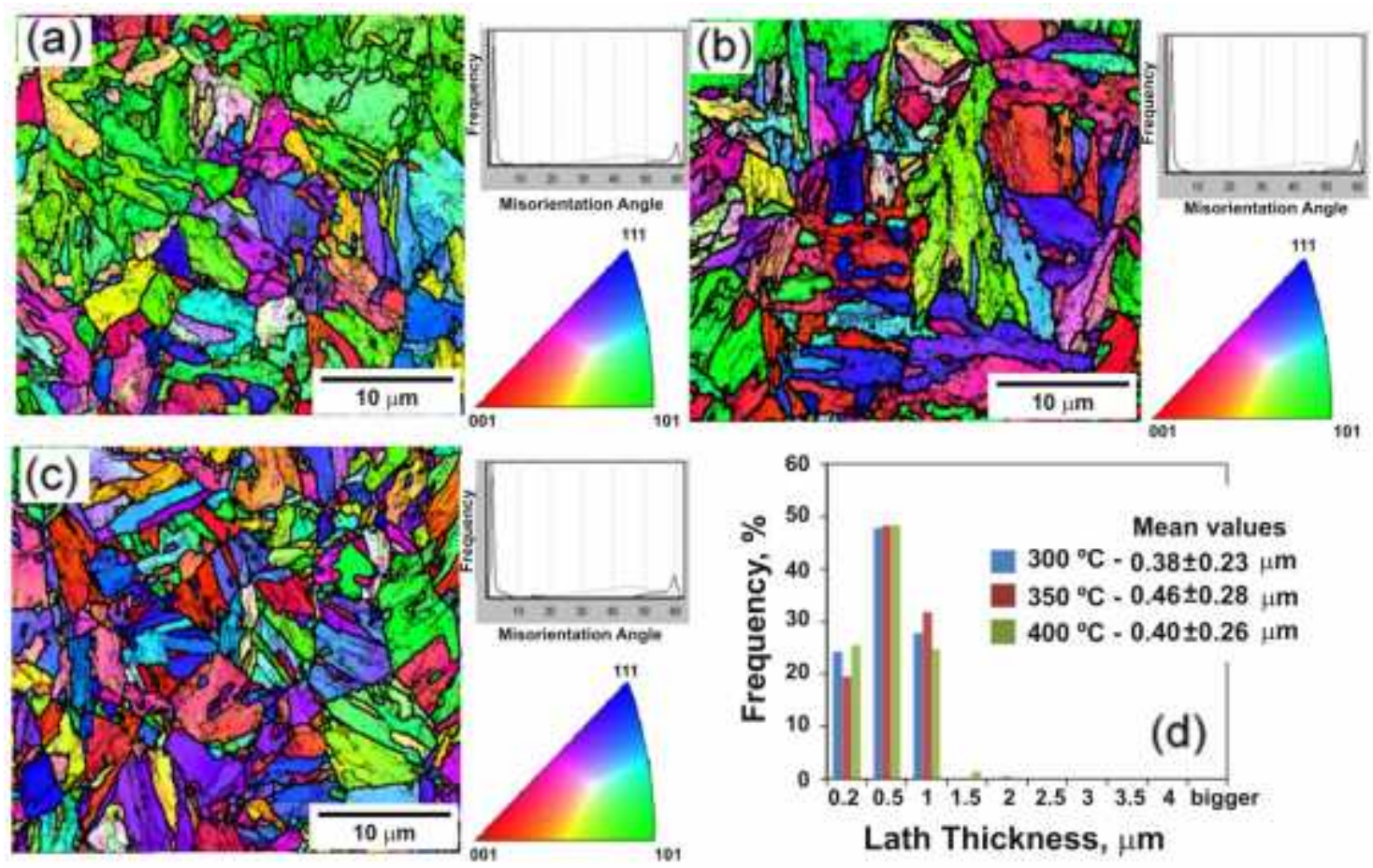

Figure 11.- Orientation imaging map, misorientation map (tolerance angle of $10^{\circ}$ for high angle boundaries and tolerance angle of $2^{\circ}$ for low angle boundaries) and corresponding misorientation frequency graph of lath-like ferrite matrix in annealed CR2 steel at different bainite holding temperatures: (a) $400{ }^{\circ} \mathrm{C}$; (b) $350{ }^{\circ} \mathrm{C}$ and (c) 300 ${ }^{\circ} \mathrm{C}$ measured by EBSD with a $0.1 \mu \mathrm{m}$ step size;. (d) Ferrite lath thickness distribution and corresponding average values as a function of transformation temperature. 

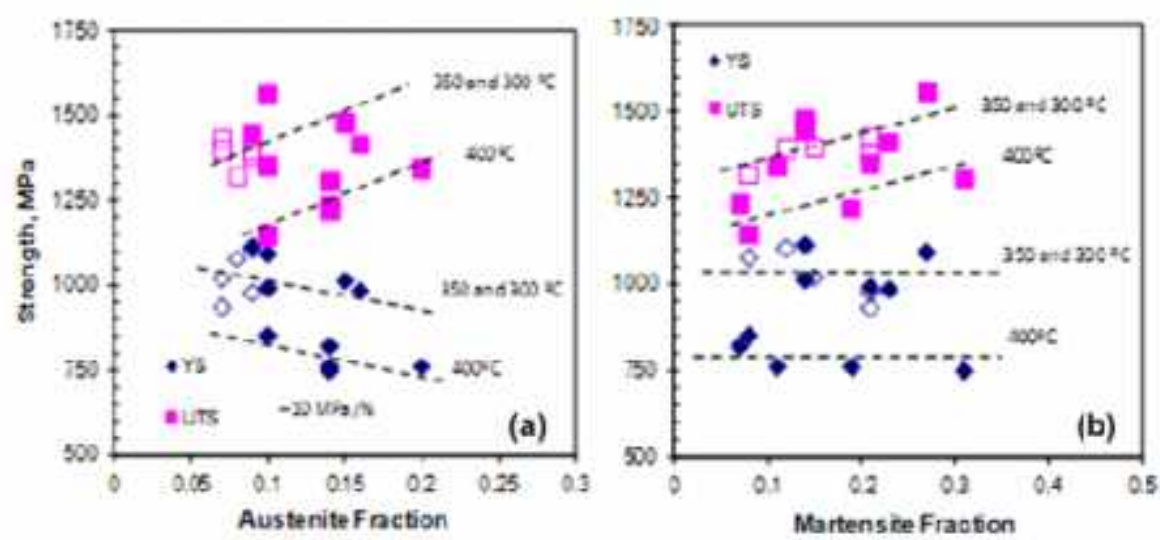

Figure 12.- Effect of (a) retained austenite and (b) martensite on strength of annealed cold rolled steels. Hollow symbols correspond to samples transformed below Ms temperature. 

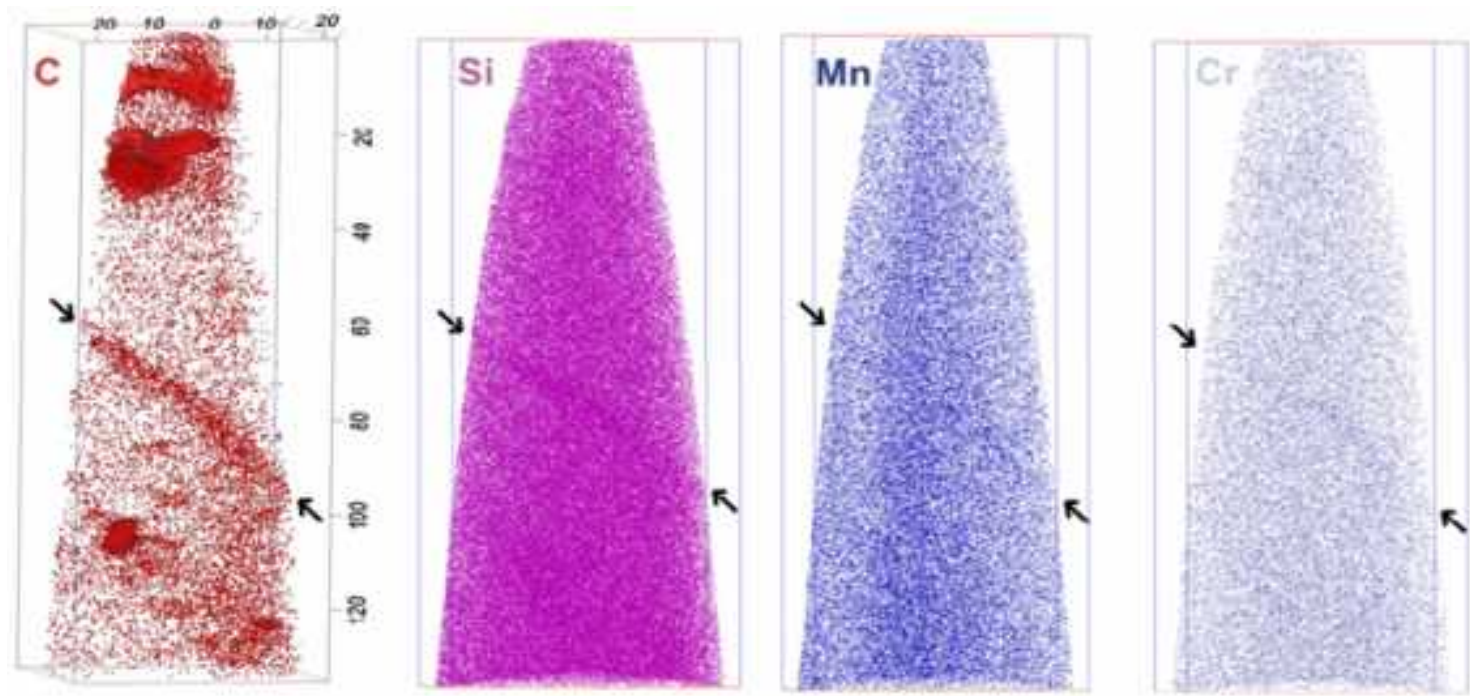

Figure 13.- Carbon isoconcentration surfaces at $1 \mathrm{wt} \% \mathrm{C}$ superimposed with the carbon atom map, and solute atom maps showing carbon clusters in bainitic ferrite and solute segregation on inter-lath boundary in a steel Fe-0.3C-2Mn-1.5Si-0.4Cr (wt. \%) transformed at $350{ }^{\circ} \mathrm{C}$ for $20 \mathrm{~min}$. 


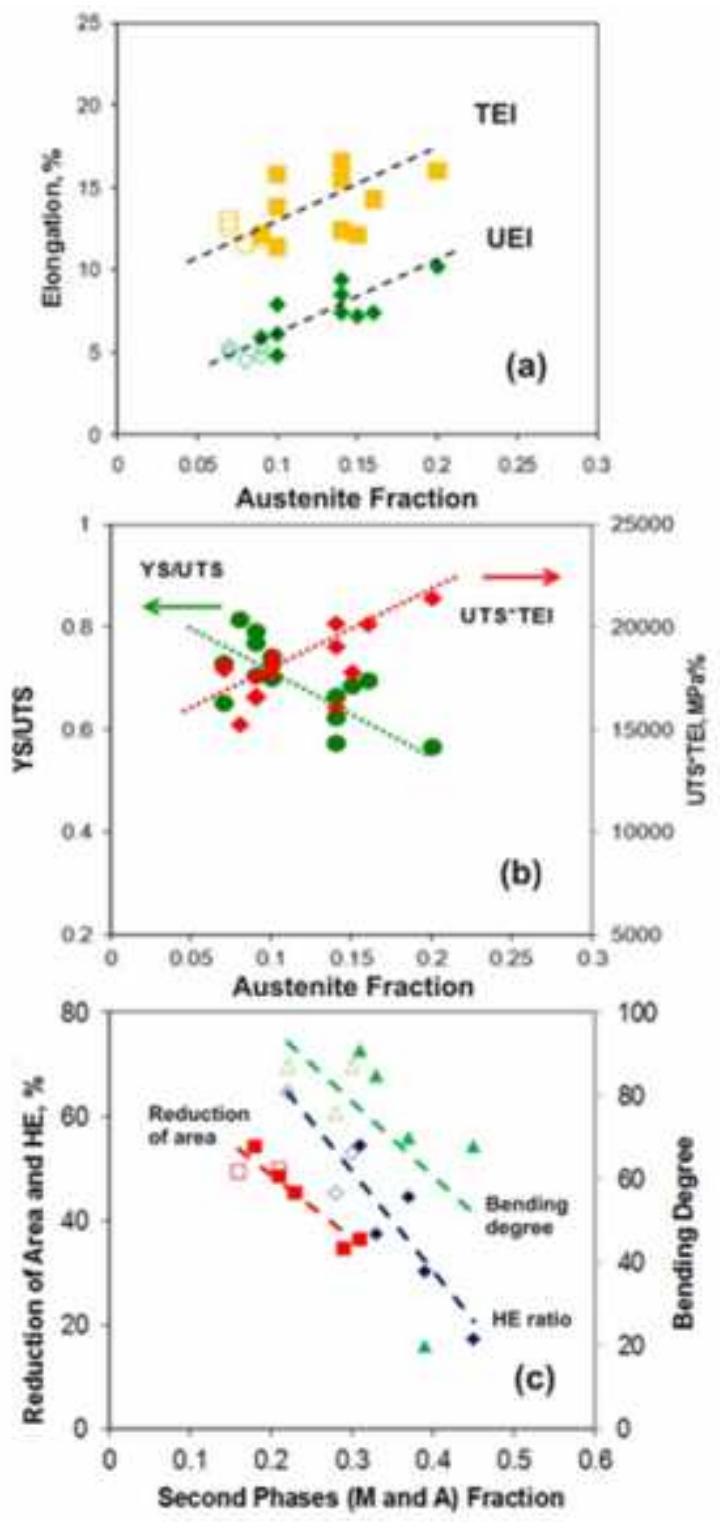

Figure 14.- Effect of retained austenite on (a) elongations, (b) YS/UTS ratio, and (c) reduction of area and formability performance (HE ratio and maximum bending degree) of annealed cold rolled bainitic steels. Hollow symbols correspond to samples transformed below Ms temperature. 

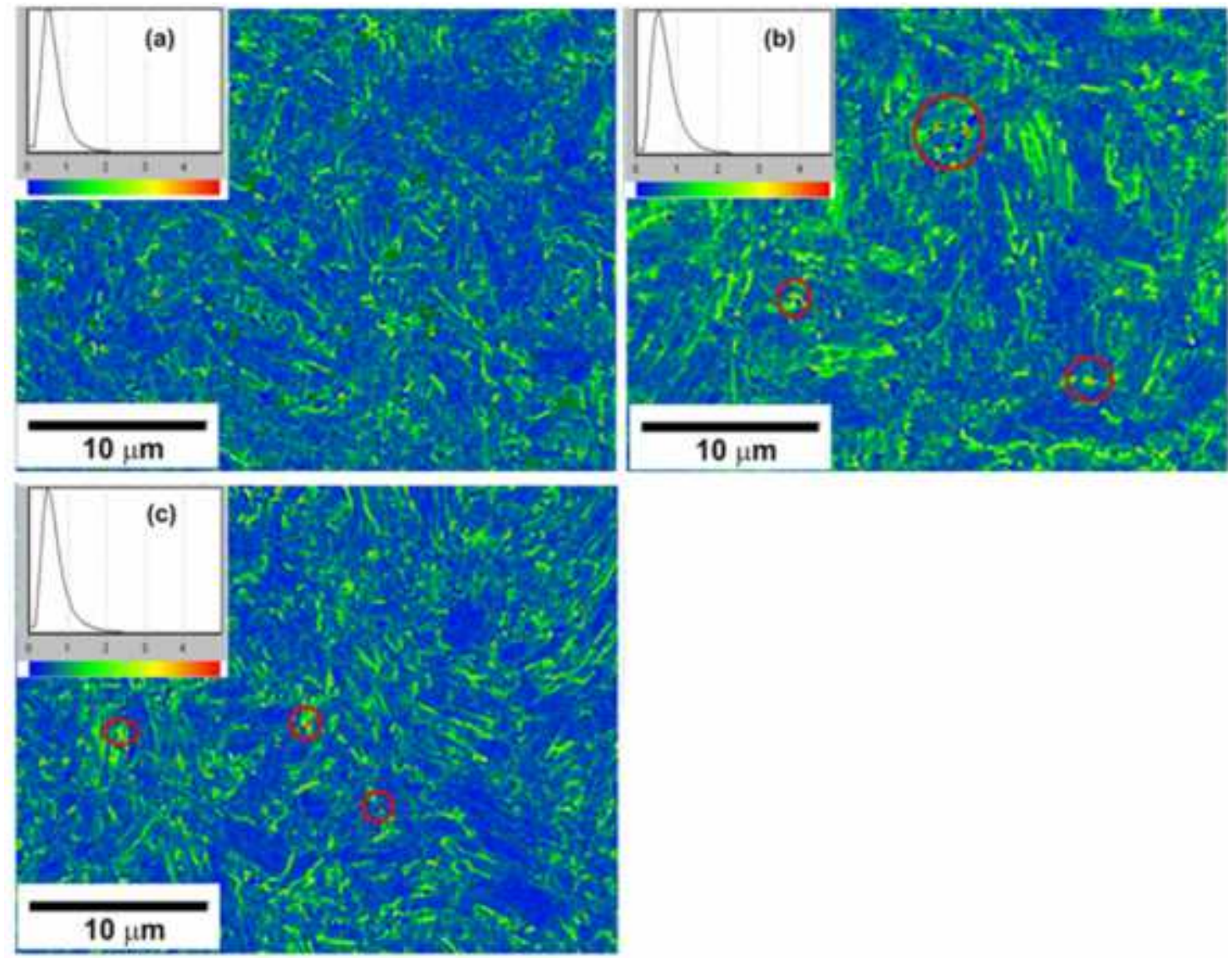

Figure 15.- Kernel maps and corresponding local misorientation distribution of lathlike ferrite measured by EBSD with a $0.1 \mu \mathrm{m}$ step size in annealed CR2 steel at different overaging temperatures: (a) $400{ }^{\circ} \mathrm{C}$; (b) $350{ }^{\circ} \mathrm{C}$ and (c) $300{ }^{\circ} \mathrm{C}$. 

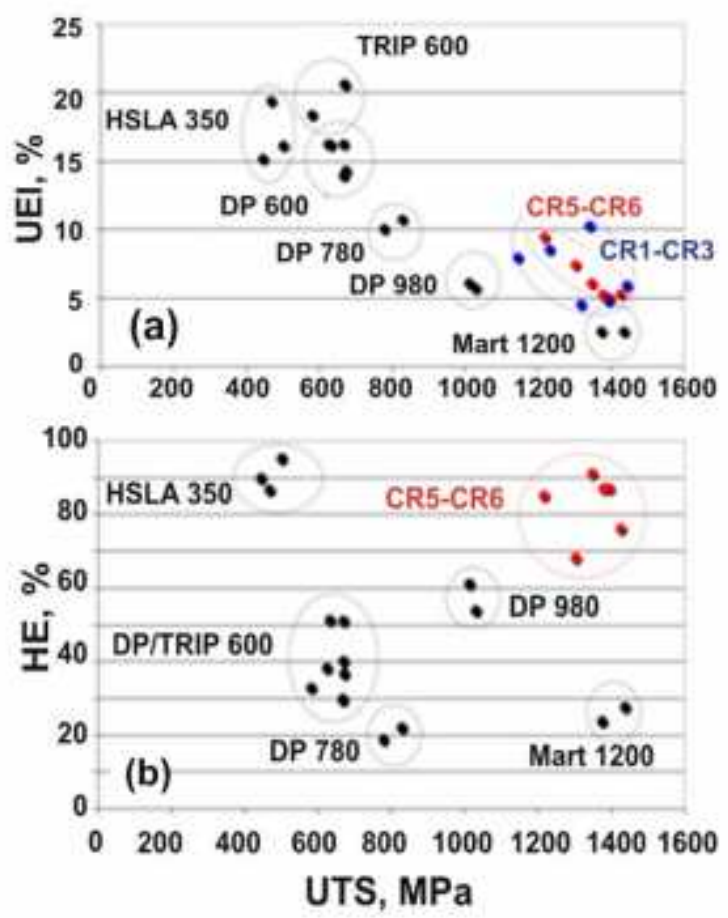

Figure 16.- Performances of designed annealed cold rolled steels compared to high strength steels commercially available for coldstamping or cold-forming products: (a) UEl and (b) HE ratio as a function of UTS. 